Climate Change Expert Group

Paper No. 2013(4)

\title{
Exploring Climate Finance Effectiveness
}

Jane Ellis, Randy Caruso and Stephanie Ockenden (OECD) 


\section{OECD/IEA CLIMATE CHANGE EXPERT GROUP PAPERS}

This series is designed to make available to a wider readership selected papers on climate change issues that have been prepared for the OECD/IEA Climate Change Expert Group (CCXG). The CCXG (formerly called the Annex I Expert Group) is a group of government delegates from OECD and other industrialised countries. The aim of the group is to promote dialogue and enhance understanding on technical issues in the international climate change negotiations. CCXG papers are developed in consultation with experts from a wide range of developed and developing countries, including those participating in CCXG Global Forums.

The full papers are generally available only in English.

The opinions expressed in these papers are the sole responsibility of the author(s) and do not necessarily reflect the views of the OECD, the IEA or their member countries, or the endorsement of any approach described herein.

Comments on the series are welcome, and should be sent to env.contact@oecd.org or the Environment Directorate, 2 rue André Pascal, 75775 PARIS CEDEX 16, France.

\section{OECD/IEA Climate Change Expert Group Papers are published on www.oecd.org/env/cc/ccxg.htm}

Applications for permission to reproduce or translate all or part of this material should be made to: OECD Publishing, rights@oecd.org or fax 33145249930.

This document has been produced with the financial assistance of the European Union. The views expressed herein can in no way be taken to reflect the official opinion of the European Union.

\section{Copyright OECD/IEA, 2013}

Applications for permission to reproduce or translate all or part of this material should be addressed to: Head of Publications Service, OECD/IEA

2 rue André-Pascal, 75775 Paris Cedex 16, France

or

9 rue de la Fédération, 75739 Paris Cedex 15, France 


\begin{abstract}
Exploring Climate Finance Effectiveness

Ensuring that climate finance is used effectively will help to maximise its impact. The effectiveness of climate finance can be defined as the extent to which an activity attains its stated aims. These aims can vary, depending on the source of climate finance and how it is channelled. There are therefore different views on what "effective" climate finance is, as well as on how this effectiveness can be assessed. This paper explores how different communities view climate finance effectiveness; the policies or institutional pre-conditions that facilitate effectiveness; and how effectiveness is currently monitored and evaluated. The paper concludes by discussing the conflicts and trade-offs encountered in assessing effectiveness and a possible way forward in balancing multiple views and priorities.
\end{abstract}

JEL Classification: F21, F35, F55, F64, F65, G23, O2, O44, Q54, Q56

Keywords: Climate finance effectiveness, aid effectiveness, mobilise, mobilize, monitoring and evaluating

\title{
RÉSUMÉ \\ Étudier l’efficacité du financement climatique
}

En veillant à ce que le financement climatique soit rationnellement utilisé, on contribuera à maximiser son impact. L'efficacité du financement climatique peut se définir comme étant le degré de réalisation des objectifs déclarés d'une activité donnée, lesquels peuvent varier en fonction de la source et des circuits de financement. Par conséquent, les avis divergent sur ce que signifie un financement climatique " efficace », ainsi que sur la façon dont cette efficacité peut être évaluée. Ce rapport étudie comment différents milieux ou communautés considèrent l'efficacité du financement climatique, ainsi que les politiques ou les préalables institutionnels qui la favorisent et les méthodes actuellement utilisées pour assurer le suivi et l'évaluation de cette efficacité. Il conclut par une analyse des contradictions rencontrées et des arbitrages à opérer lors de l'évaluation de l'efficacité, et propose une voie à suivre pour concilier les multiples points de vue et priorités à considérer.

Classification JEL: F21, F35, F55, F64, F65, G23, O2, O44, Q54, Q56

Mots-clés: Efficacité du financement climatique, efficacité de l’aide, mobilisation, suivi et évaluation 


\section{FOREWORD}

This document was prepared by the OECD and IEA Secretariats in 2013 in response to a request from the Climate Change Expert Group (CCXG) on the United Nations Framework Convention on Climate Change (UNFCCC). The CCXG oversees development of analytical papers for the purpose of providing useful and timely input to the climate change negotiations. These papers may also be useful to national policy-makers and other decision-makers. Authors work with the CCXG to develop these papers in a collaborative effort. However, the papers do not necessarily represent the views of the OECD or the IEA, nor are they intended to prejudge the views of countries participating in the CCXG. Rather, they are Secretariat information papers intended to inform Member countries, as well as the UNFCCC audience.

Members of the CCXG are Annex I and OECD countries. The Annex I Parties or countries referred to in this document are those listed in Annex I of the UNFCCC (as amended by the Conference of the Parties in 1997 and 2010): Australia, Austria, Belarus, Belgium, Bulgaria, Canada, Croatia, Czech Republic, Denmark, the European Community, Estonia, Finland, France, Germany, Greece, Hungary, Iceland, Ireland, Italy, Japan, Latvia, Liechtenstein, Lithuania, Luxembourg, Malta, Monaco, the Netherlands, New Zealand, Norway, Poland, Portugal, Romania, the Russian Federation, Slovakia, Slovenia, Spain, Sweden, Switzerland, Turkey, Ukraine, the United Kingdom of Great Britain and Northern Ireland, and the United States of America. As OECD member countries, Korea, Mexico, Chile, and Israel are also members of the CCXG. Where this document refers to "countries" or "governments", it is also intended to include "regional economic organisations", if appropriate.

\section{ACKNOWLEDGEMENTS}

This paper was prepared by Jane Ellis, Randy Caruso and Stephanie Ockenden, OECD. The paper benefited from direct funding for the work of the CCXG programme in 2013, including from Australia, the EC, Germany, Japan, Korea, the Netherlands, New Zealand, Norway, Sweden and Switzerland and the United Kingdom, and in-kind support from the OECD and the IEA.

The authors would like to acknowledge the helpful comments on earlier drafts from their OECD/IEA colleagues Anthony Cox, Gregory Briner, Jan Corfee-Morlot, Sara Fyson, Raphaël Jachnik, Takayoshi Kato, Nicolina Lamhauge, Virginie Marchal, Mariana Mirabile, Michael Mullan, Andrew Prag, Cécile Sangaré, Rob Youngman, Sáni Zou as well as Philippe Benoit, Takashi Hattori and Christina Hood. The authors also gratefully acknowledge information provided by Inka Gnittke, Eric Haxthausen, Anton Hilber, Dima Reda, Marianne Tegman, as well as presenters and delegates at the September 2013 CCXG Global Forum.

\section{Questions and comments should be sent to:}

Jane Ellis

OECD Environment Directorate

2, rue André-Pascal

75775 Paris Cedex 16

France

Email: jane.ellis@oecd.org

All OECD and IEA information papers for the Climate Change Expert Group on the UNFCCC can be downloaded from: http://www.oecd.org/env/cc/ccxg.htm. 


\section{TABLE OF CONTENTS}

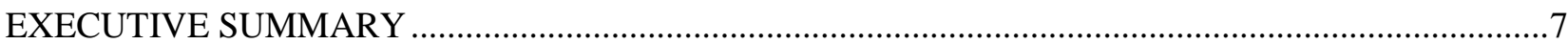

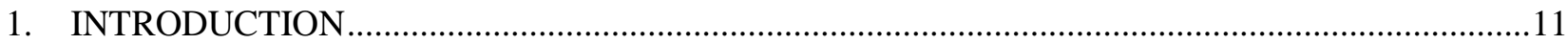

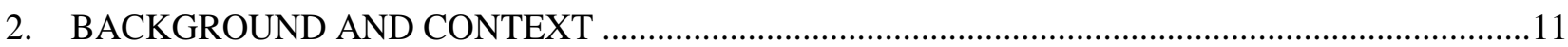

2.1 Different communities' principles and views related to effectiveness........................................12

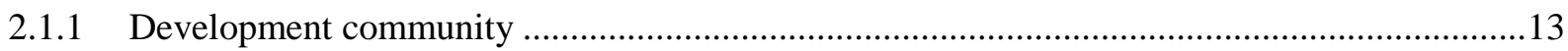

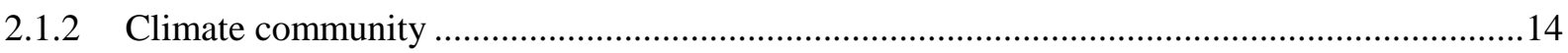

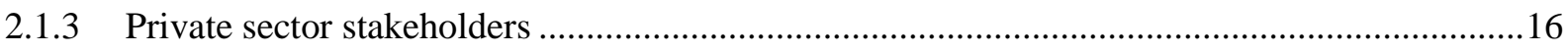

2.2 Exploring climate finance effectiveness at different stages ....................................................17

3. STRENGTHENING INTERNATIONAL AND NATIONAL INSTITUTIONS, PROCESSES, AND

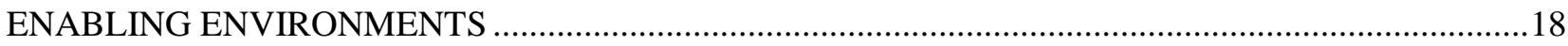

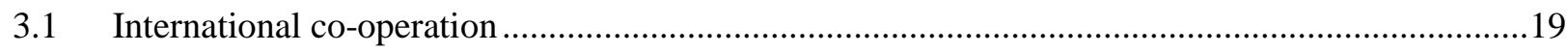

3.2 Enhancing national institutions and enabling environments ...................................................20

3.2.1 Enhancing national enabling environments for mobilising private finance .............................20

3.2.2 Enhancing national institutional capacity and country systems, readiness and implementation21

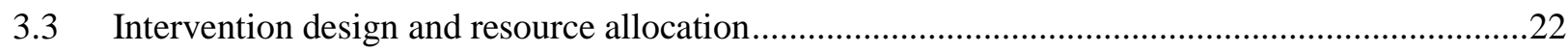

4. MONITORING AND EVALUATING RESULTS OF INTERVENTIONS........................................24

4.1 Conceptual framework for monitoring results of interventions .................................................25

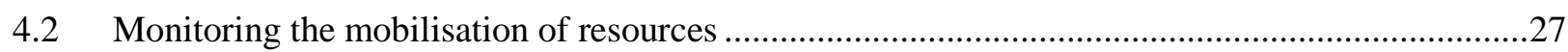

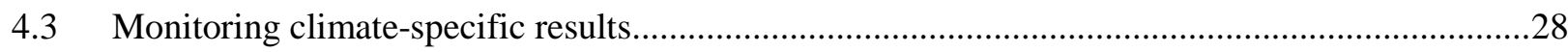

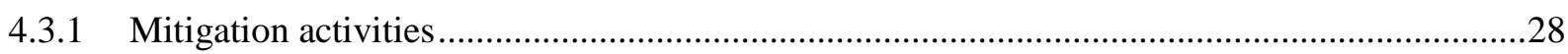

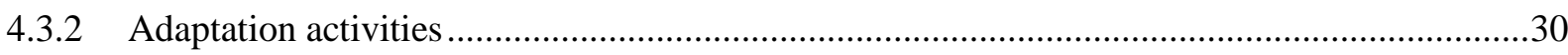

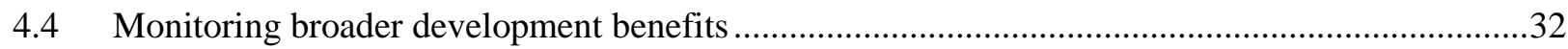

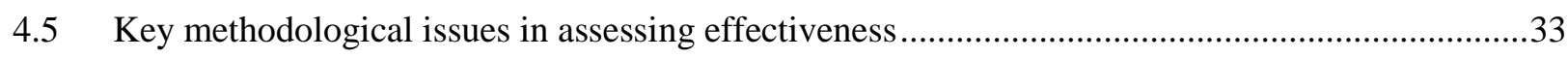

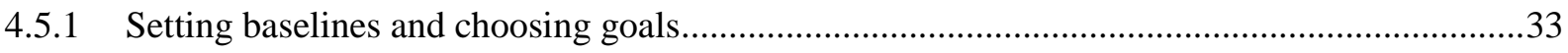

4.5.2 Assessing a "transformational change” or "paradigm shift" ....................................................33

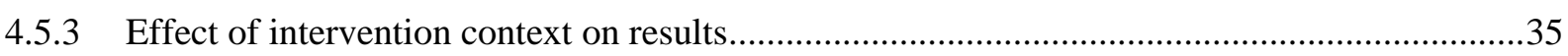

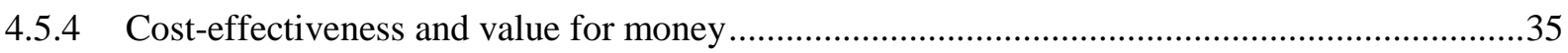

4.5.5 Complexity of underlying financial instruments ...............................................................36

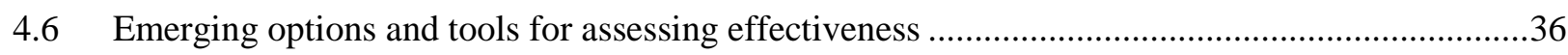

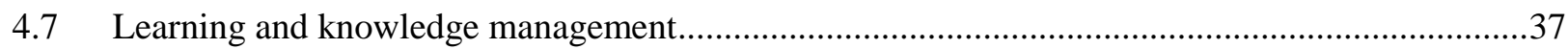

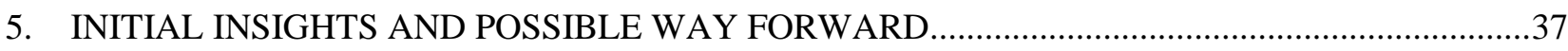

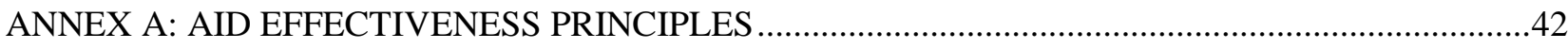

ANNEX B: THE IMPACT OF TRANSACTION COSTS AND SAFEGUARDS ON EFFECTIVENESS44

ANNEX C: ASSESSING BROADER DEVELOPMENT BENEFITS …....................................................46

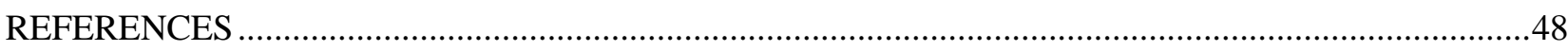

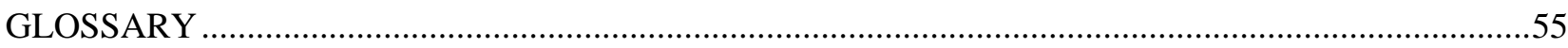




\section{LIST OF TABLES}

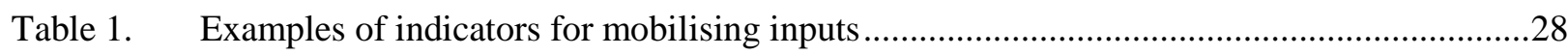

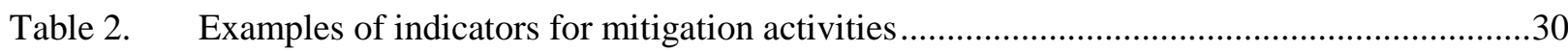

Table 3. Examples of indicators for adaptation activities...............................................................31

\section{LIST OF FIGURES}

Figure 1. Coverage of existing principles relevant to international climate finance effectiveness.......12

Figure 2. Aspects of climate finance issues emphasised by different communities .............................13

Figure 3. Considering effectiveness at different stages .................................................................18

Figure 4. Conceptual framework for monitoring results of interventions............................................26

Figure 5. Difficulty of attributing impacts to discrete interventions...................................................34 


\section{Executive summary}

Significant expansion of climate finance for developing countries is needed in order to enable a shift towards low-emission, climate-resilient development pathways. To facilitate this transition, developed countries formalised a commitment to mobilise USD 100 bn per year by 2020 at the $16^{\text {th }}$ Conference of the Parties (COP) to the United Nations Framework Convention on Climate Change (UNFCCC).

Quantifying the level of climate finance mobilised is important for transparency in assessing progress towards this commitment. However, while the quantity of climate finance is important, quantity alone is not sufficient to achieve the climate objectives of the Convention: it is a "means to an end" and not an end in itself. Ensuring the underlying quality, or effectiveness, of climate finance will also be crucial. This paper explores the following issues: (i) how different communities view climate finance effectiveness; (ii) the policies or institutional pre-conditions that facilitate effectiveness; and (iii) how effectiveness can be monitored and evaluated. The paper also discusses the conflicts and trade-offs encountered in assessing effectiveness and proposes a possible way forward that balances multiple views and priorities.

\section{What is climate finance effectiveness?}

Adequately addressing the range of issues to mitigate and adapt to climate change and achieving the scale of climate finance required to do so will necessarily involve a variety of different communities (e.g. development, climate, and the private sector). These communities represent the perspectives of developed and developing countries, as well as both public and private sources of climate finance. In its simplest sense, effectiveness of climate finance can be defined as the extent to which an intervention achieves its stated aim(s). Thus, according to their varying aims or objectives, each community may emphasise different aspects when assessing the effectiveness of their intervention.

The development and climate communities, as well as some actors in the private sector, have laid out their perspectives on important issues related to enabling and delivering effective climate finance. A key pillar to this is the development community's Paris Declaration on Aid Effectiveness (2005). This was agreed to by more than 130 countries and lays out agreed principles for effective development finance that also cover climate-related aid: these principles relate to country ownership, alignment, harmonisation, results and mutual accountability. The subsequent Busan Partnership on Effective Development Co-operation (2011), agreed to by 150 countries, outlines the importance of climate finance as well as extending the scope of these principles beyond aid to cover development finance and development co-operation more broadly.

The climate community (i.e. those involved in the UNFCCC climate negotiations) has agreed on principles governing climate finance. These include both general principles as well as those developed in the context of funds established by the UNFCCC process such as the Green Climate Fund and the Global Environment Facility. Within the climate community, the framing of effectiveness has changed over time, primarily reflecting changes in the development community's provisions on aid effectiveness. Additionally, while not homogenous, some within the private sector have adopted certain principles or environmental and social safeguards (e.g. the Equator Principles). However, a key requirement for effective private investment generally involves maximising risk-adjusted returns.

There is significant and growing common ground between the different communities (Figure ES-1). For example, all agree that scaled-up climate finance is needed, that both public and private sources can play a key role, and that the (self-) sustainability of a project and transparency is important. However, different communities may naturally place greater emphasis on different aspects of effectiveness. For example, meeting the urgent and immediate needs (especially adaptation needs) of climate-vulnerable countries is important to the development and climate communities, but may not necessarily be a priority of the private 
sector. These differences in emphasis and priority could make distilling a common definition of climate finance effectiveness challenging, and whilst common and clear understanding is important, it is not clear that a single definition is necessary.

In practice, institutions within these communities often design and manage interventions to address multiple aims. Such multi-dimensional approaches to effectiveness involve a combination of objectives, such as mobilising resources, maximising broader development benefits, achieving climate-related objectives, and/or building capacity. For example, a monoculture plantation might be an effective intervention that focuses solely on maximising mitigation potential. However, interventions balancing multiple objectives (e.g. mitigation, biodiversity, development) may favour mixed plantation or agroforestry activities that provide greater biodiversity and other benefits (food, medicinal plants, etc.).

Figure ES 1: Aspects of climate finance issues emphasised by different communities

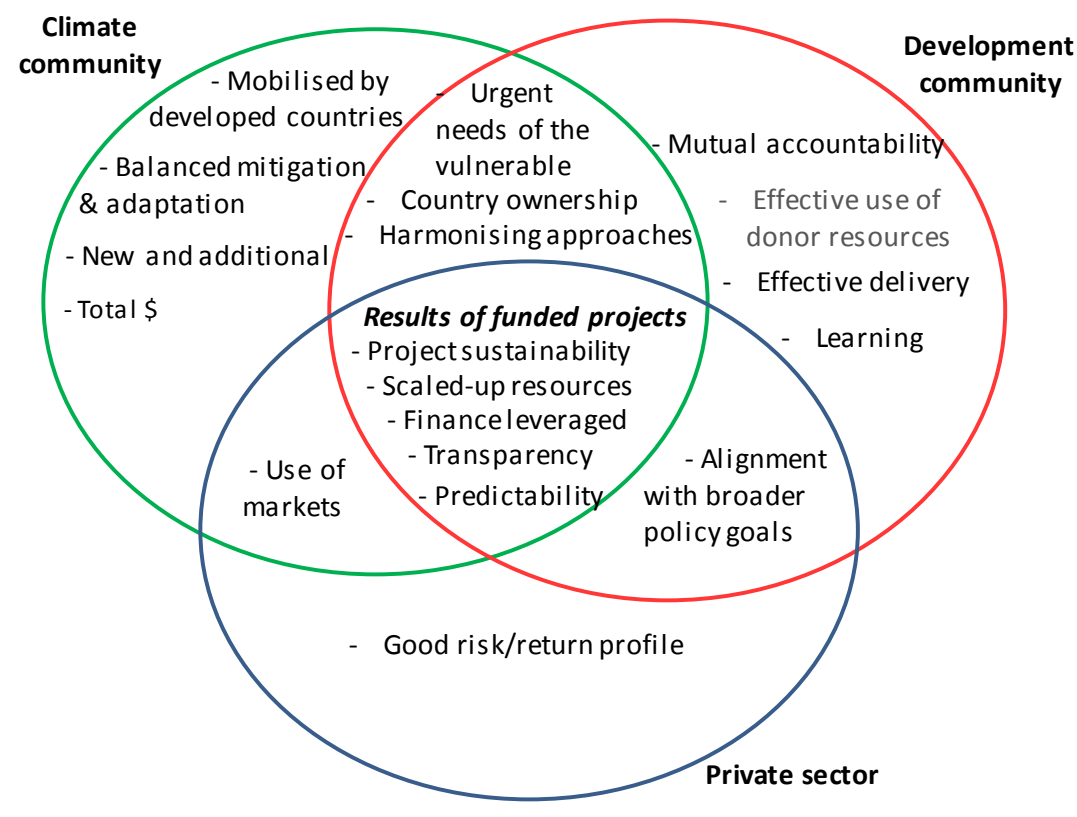

\section{Where does the concept of effectiveness apply?}

In addition to varying definitions of what effectiveness entails, the concept of effectiveness can be applied at different stages involved in the planning, delivery, and use of climate finance. These include cooperating internationally; enhancing national institutions, processes, and enabling environments; designing interventions and allocating resources; and measuring results. The development community in both developed and developing countries emphasises the importance of supporting country ownership and alignment with national priorities, as articulated in agreed aid effectiveness principles. The underlying logic in these principles is that international co-operation and capacity building within national and local institutions can help to establish enabling environments that channel, deliver and manage climate finance more effectively. Focusing on institutional aspects of effectiveness will also be crucial in creating the conditions and capacities necessary for transformational changes within countries. 


\section{How is climate finance effectiveness assessed?}

Assessments of whether a specific intervention is effective or not will be influenced by its specific aims and the stage at which the intervention is targeted. Even when interventions are targeted towards similar aims, assessments of effectiveness may differ due to a number of internal and external variables. These include the:

- Context within which an intervention occurs. This can include national, institutional or local/sitespecific issues. At the national level, it is difficult for donors to meet the aid effectiveness principle of aligning their inputs with country priorities if a developing country has not yet established such priorities. At the institutional level, varying national circumstances or enabling environments can enhance or inhibit an intervention's success (e.g. a regulatory environment's influence on an intervention's ability to mobilise private finance). Site-specific environmental factors can also influence the performance of an intervention (e.g. a wind turbine will generate varying amounts of electricity depending on the prevailing wind speed).

- Time horizon of the assessment. Some climate interventions can give rise to immediate results (e.g. energy efficiency projects). However, some interventions will target results that can only be assessed after an extended period of time (e.g. constructing infrastructure that can withstand a 1-in100 -year flood). These different time horizons for the results of an intervention mean that effectiveness levels will vary depending on when results are assessed. Choosing an appropriate point in time for assessment can be particularly complicated for climate finance interventions aimed at long-term transformational impacts.

- Scale at which effectiveness is assessed. Depending on its aims, an intervention may seek results at the project, national, or international scale. This will have implications for how its effectiveness is assessed. For example, an intervention that seeks to promote transformational change in a given sector may be judged effective at the project-level if it produces the expected outputs (e.g. off-grid renewable electricity, number of people trained in drought-resistant agriculture). However, if the intervention is not replicated at scale, the transformational impacts of the intervention will be limited.

\section{Challenges and way forward}

The multi-faceted nature of how effectiveness is viewed, the stages at which it can be applied, and how it is assessed results in a number of complexities. These can be grouped into three main challenges:

- Accommodating the different governing principles and priorities of a variety of actors (those who provide, channel and use climate finance) involved in a climate finance intervention.

- Balancing a need to demonstrate immediate results attributable to specific interventions (which may be easier to assess for project-level outputs) with broader aims (which may be better assessed at a sectoral or national level). Such aims could include promoting lesson learning and supporting effective processes (e.g. at sectoral or national levels), which often requires mainstreaming climate concerns, aligning with government priorities, and/or achieving longer-term transformational impacts.

- Identifying the most appropriate ways of focusing scarce resources to maximise results across multiple dimensions (e.g. climate, development, economic, and financial). 
In terms of the way forward for assessing effectiveness, there is already a significant body of information upon which to build. For example, many providers of public international climate finance have identified the different results (e.g. climate, development, social, economic) that can be expected from different types of interventions. Identifying lessons from this experience and learning from this will be important. Assessing results, as well as identifying effective pre-conditions and modalities for delivering climate finance, can be an iterative process and involve making trade-offs. Key questions for future development of frameworks to assess effectiveness are:

- To what extent do principles of development effectiveness (which apply to international public climate-related aid and other official flows) apply to or influence private climate finance mobilised by public climate finance, measures and policies?

- Should results frameworks used to assess the effectiveness of climate interventions focus solely on the climate results of an intervention, or also encompass broader development benefits?

- How flexible should assessment tools be (to deal not only with different types of interventions, but changing national and international priorities and frameworks over time)?

- How to further increase harmonisation of results frameworks at different scales and levels (e.g. project-level monitoring and evaluation; donor, intermediary, and fund-level systems; and national development plan goals) both within the area of climate finance, and in other relevant areas (e.g. post-2015 sustainable development goals)?

- Over what scales and time horizons to fund, implement, and track results of climate interventions? 


\section{Introduction}

Provision of climate finance to developing countries has been growing in recent years. It will need to continue to expand significantly in order to meet the climate finance commitment formalised in 2010 at the UN Framework Convention on Climate Change (UNFCCC) $16^{\text {th }}$ Conference of the Parties (COP) for developed countries to mobilise USD 100 bn per year by 2020 from a variety of sources to meet the needs of developing countries. The phrasing of this commitment means that significant attention to date has focused on quantifying international climate finance provided to developing countries.

While the quantity of climate finance is important, it is a "means to an end" and not an end in itself. Thus, it is also important that climate finance is used effectively, as this can help to mobilise further climatefriendly investment, and thus facilitate the transition to a low-carbon, climate-resilient future. This is true for those that provide the basis for public and private climate finance, e.g. taxpayers in developed countries and shareholders in companies making climate investments. It is also true for those facing the effects of climate change in developing countries.

The importance of effectiveness is acknowledged in the 1992 UNFCCC, as well as subsequent decisions. More recently, effectiveness is mentioned in the core mandate of the Green Climate Fund (GCF), which could deliver a substantial proportion of the USD 100 bn, and is to "operate in a transparent and accountable manner guided by efficiency and effectiveness” (UNFCCC, 2011).

However, assessing the effectiveness of climate finance is not a straightforward task. As outlined in previous analysis for the CCXG, there is no agreement to date on which activities, flows and interventions are to be labelled "climate finance" (see e.g. Clapp et al., 2012), or what constitutes "mobilised" climate finance (see e.g. Caruso and Ellis, 2013). Similarly, there is no common understanding of what is meant by "effectiveness". While there is overlap in views between different stakeholders on what climate finance effectiveness is, there are also differences. These differences relate to the aims, sources, and channels of finance for the intervention. In addition, there are differences in how climate finance effectiveness is assessed.

A clearer understanding of climate finance effectiveness would therefore be useful to the international community. This paper explores different aspects of climate finance effectiveness, for example in terms of climate finance outcomes (e.g. environmental, economic, developmental), delivery (e.g. institutions and governance), and time horizons (e.g. short-term vs. long-term results). The paper uses examples from different types of activities (both mitigation and adaptation) and explores the issue of effectiveness at a range of scales (projects, programmes, policies). The paper focuses on climate finance in the context of the UNFCCC, i.e. public climate finance, as well as the private climate finance mobilised by public interventions. Section 2 outlines key issues and/or principles for climate finance, as highlighted by different communities active in providing, channelling or using it. Section 3 explores the enabling environments, institutions and processes important to ensuring that climate interventions can be effective. Section 4 examines how different institutions treat climate finance effectiveness and how results of climate interventions are measured. Initial conclusions and possible ways forward are presented in Section 5. Issues related to domestic financing by non-Annex I countries of climate responses, the total level and flows of climate finance, and discussion of the effectiveness of different financial instruments are outside the scope of this paper.

\section{Background and context}

As the level of climate finance increases, there is also increasing interest and need in ensuring that this finance is effective (e.g. Bird et. al., 2013; Brown et. al., 2011; and Thornton, n.d.). Principles relevant to climate finance effectiveness have been agreed by developed and developing countries at international, 
institutional and fund level, and cover selected private and public flows. However, to date there is no single set of principles or definition governing "climate finance effectiveness". This section outlines the similarities and differences between existing views and principles, as well as other issues identified as important for climate finance by the development, climate, and private sector communities.

\subsection{Different communities' principles and views related to effectiveness}

International climate finance, consistent with decisions taken at the international climate negotiations in Bali and later affirmed in Copenhagen and Cancun, "may come from a wide variety of sources, public and private, bilateral and multilateral, including alternative sources” (UNFCCC, 2010). Thus, international climate finance often involves a broad range of stakeholder communities and types of financial flows. These communities have differing motivations and views on what aspects of climate finance are important, and what makes climate finance effective. These views have been expressed in agreements, principles, or other texts (Figure 1). These different views and agreements will influence the aims and objectives of climate finance and how its effectiveness is assessed. For example:

- For climate-related finance to be counted as Official Development Assistance (ODA), it is required, by definition, ${ }^{1}$ to promote the economic development and welfare of developing countries, and can be judged against established aid effectiveness principles (see Annex A).

- For the private sector to invest into climate-related activities, climate-related investments will need to have an attractive ratio of investment risk to returns.

Figure 1. Coverage of existing principles relevant to international climate finance effectiveness

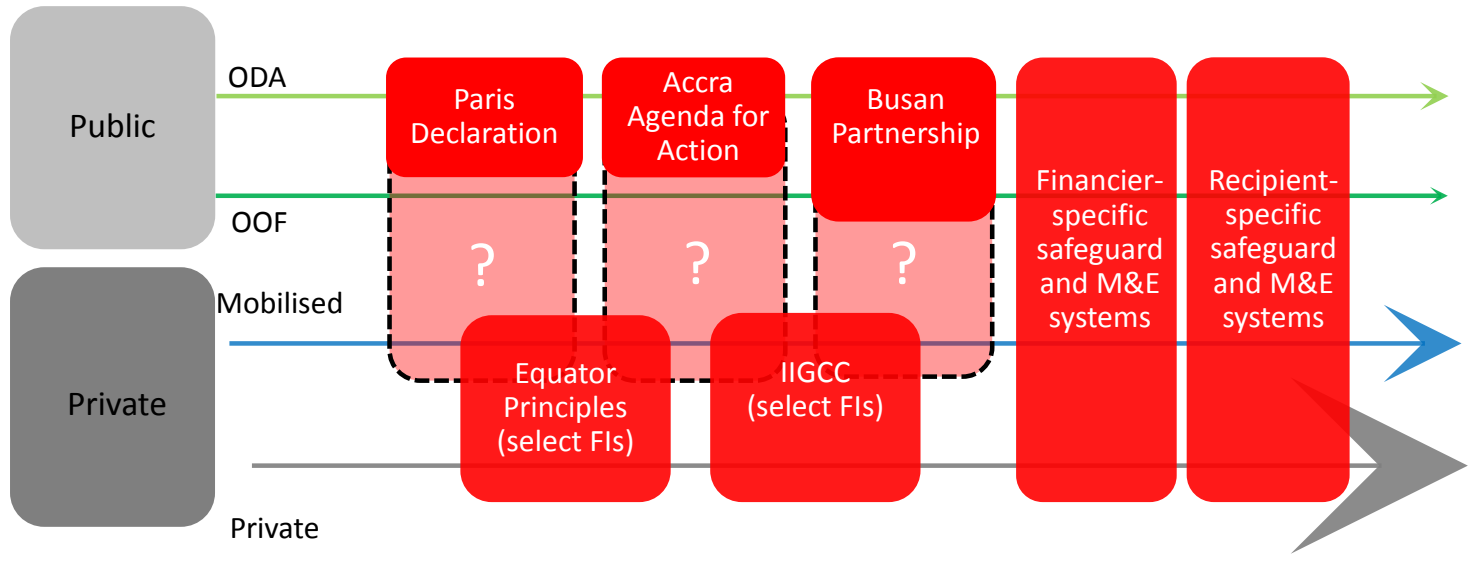

$\mathrm{OOF}=$ other official flows

Specific requirements and safeguards for private climate finance (including "mobilised" climate finance) may also exist. For example, carbon market finance, as well as finance from carbon funds, are likely to continue to be subject to their own standards and principles, e.g. on accreditation, monitoring, reporting and verification. In some instances, agreements on safeguards such as the Equator Principles on managing risks (prior to project approval) apply. In addition, the Institutional Investors Group on Climate Change (IIGCC), which includes pension funds and asset managers representing assets of around USD 10 trillion, has developed policy recommendations on promoting low-carbon investment, which include some relevant

\footnotetext{
${ }^{1}$ OECD DAC definition, further details are provided in the Statistical Reporting Directives (available at www.oecd.org/dac/stats/dac/directives).
} 
principles (IIGCC, 2011). On top of these agreements, donors, financial intermediaries, and host countries often have specific environmental, social, and financial safeguards and monitoring and evaluation systems relating to specific climate finance sources, channels and/or uses.

As exemplified by these existing principles, views on what climate finance effectiveness is may also differ across stakeholder communities (e.g. development, climate, and private sector). Moreover, the extent to which processes and results of international climate finance are judged "effective" will depend on the objectives of that international climate finance - which can vary. Whilst the OECD DAC (2010a) has a definition for development effectiveness (see Box 4), the number and range of climate finance providers ${ }^{2}$ and diversity of recipients with different needs and priorities does not give rise to a common set of objectives (Zou and Ockenden, 2013). Some of these perspectives may be mutually compatible (e.g. where adaptation and climate resilient benefits are closely aligned with national development and poverty reduction goals). However, in other instances there may be trade-offs; for example, between maximising global public benefits (e.g. GHG emission reductions) versus interventions with both global and local public benefits. The different perspectives and common ground shared by these communities are highlighted in Figure 2 below.

\section{Figure 2. Aspects of climate finance issues emphasised by different communities}

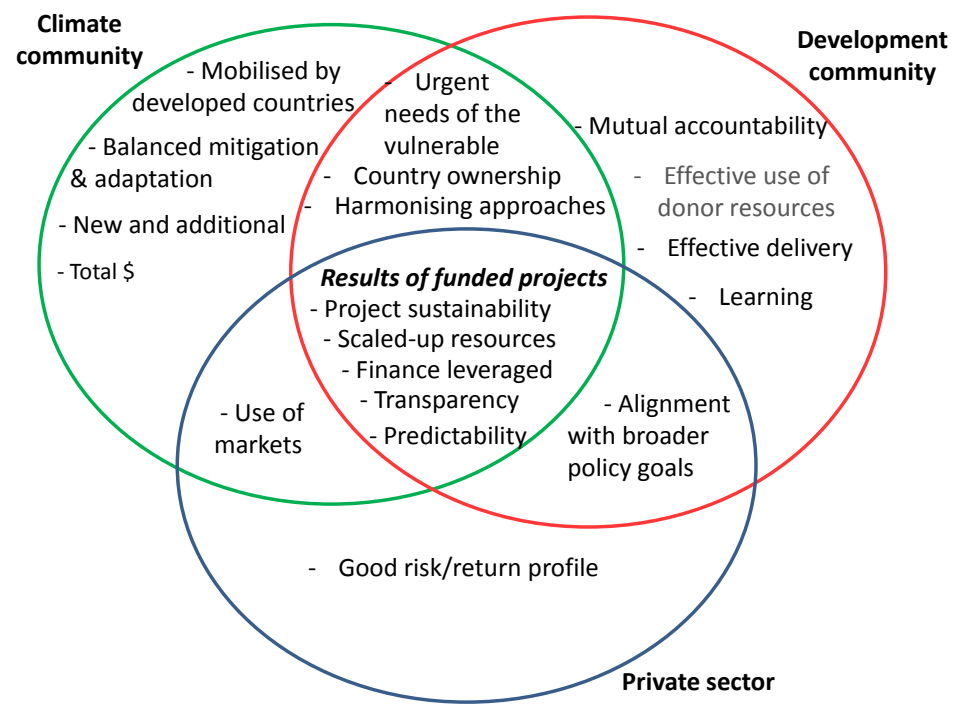

This figure highlights that there are some common principles that are shared across development, climate, and private sector stakeholder communities. The area of overlap has been increasing over time. This is to be expected, as initial views from the climate community on climate finance (e.g. as it relates to the GEF) were elaborated in 1998 - well before the Paris Declaration on Aid Effectiveness was agreed in 2005. However, there remain some issues that are of more importance for only one or two of these communities.

\subsubsection{Development community}

There have been several international agreements within the development community relating to aid effectiveness that are also relevant to climate finance. In the Paris Declaration on Aid Effectiveness (2005 - henceforth Paris Declaration), donor and partner countries, as well as development financial institutions,

\footnotetext{
${ }^{2}$ Including from the climate and development finance communities, and bilateral donors, multilateral financial institutions and national development banks.
} 
other organisations and civil society, agreed principles on aid effectiveness. Outlined in Box 1, these principles are based on the expectation that effective national and international processes will enable effective outcomes. The Paris Declaration commitments were subsequently deepened by the Accra Agenda for Action endorsed in 2008 (see Annex A), which called on donors and partner countries to step up the implementation of the aid effectiveness principles.

In more recent developments, the Busan 4th High Level Forum on Aid Effectiveness (2011) made explicit the link between the aid effectiveness principles (Annex A) and international climate finance. In particular, climate finance was outlined as a priority for effective international development, to "continue to support national climate change policy and planning as an integral part of developing countries' overall national development plans, and ensure that - where appropriate - these measures are financed, delivered and monitored through developing countries' systems in a transparent manner” (OECD, 2011b). The Manila Consensus on Public Financial Management (2011) and New Consensus on Effective Institutions (2011) also highlight the importance of integrating aid effectiveness principles into climate finance. The post-2015 Sustainable Development Goals (SDGs) that are to be developed under the auspices of the UN are intended to be a reflection of global development priorities. When finalised, the SDGs could therefore also cover issues related to the effectiveness of climate interventions in addressing and mainstreaming development needs, and vice versa.

A recent OECD survey of 32 practitioners in international climate finance and development co-operation revealed high awareness and a general recognition of the aid effectiveness principles with respect to international climate finance (Zou and Ockenden, 2013). The premise is that the aid effectiveness principles of country ownership, alignment, harmonisation, results and mutual accountability can drive effective climate finance on the expectation that effective outcomes can be enabled through effective national and international processes. Some developing countries have however indicated that climate finance has "ignored" the aid effectiveness principles (Ma, 2013) or remains donor-driven (e.g. Nelson 2013; Norrington-Davies, 2011). Others cite poor access, lack of readiness and the inability to track climate-related results through country systems as barriers to applying the aid effectiveness principles to climate finance in practice (Zou and Ockenden, 2013).

Whilst recognising that not all international climate finance is ODA or public finance, climate-related aid to date is significant. In 2010 and 2011, climate-related aid commitments ${ }^{3}$ reported to the OECD DAC ${ }^{4}$ ranged on average from USD 12.8-21.1 bn per year (based on lower and upper bound estimates), representing up to $16 \%$ of total ODA. Going forward, climate-related ODA is expected to remain both significant and substantial given its potential to mobilise other sources of climate finance and given the internationally-agreed target of devoting $0.7 \%$ GNI to ODA).

\subsubsection{Climate community}

The issue of effective climate support has also been regularly highlighted within the climate community, particularly in the context of the UNFCCC. This includes: the Global Environment Facility $\left(\mathrm{GEF}^{5}\right)$ -

\footnotetext{
${ }^{3}$ Defined by the OECD DAC CRS Rio marker methodology is both broader and narrower than information that has been reported to the UNFCCC to date under Fast Start Finance, given varying reporting approaches by Parties. Going forward the definition of public climate finance and consistency with OECD DAC Rio markers is to be determined.

${ }^{4}$ OECD DAC Statistics (2013). Principal climate-related aid estimated at USD 12.8 bn on average per year over 2010 to 2011, with total climate-related aid, including principal and significant activities estimated at USD 21.1 bn on average over 2010 to 2011, based on reported donor commitments to the OECD DAC.

5 The GEF is also entrusted with operating other funds created by the UNFCCC process, including the Least Developed Countries Fund and Special Climate Change Fund.
} 
funded from public sources; the Adaptation Fund - funded by private sources via the Clean Development Mechanism as well as directly by donor governments; and the Green Climate Fund (GCF) - designed to channel both public and private funds, but not yet disbursing funds. The framing of the effectiveness issue has changed over time, primarily reflecting changes in the international community's provisions on aid effectiveness.

In the context of the GEF, two aspects of effectiveness are outlined: that of the activities funded (i.e. results); and the provision of financial resources to developing countries. The review of the financial mechanism (initially done in 1998, decision 3./CP.4 - see UNFCCC, 1998) also included certain criteria for evaluating effectiveness related to the:

- transparency of decision-making processes

- adequacy, predictability and timely disbursement of funds for activities in developing country Parties

- responsiveness and efficiency of the GEF project cycle and expedited procedures, including its operational strategy, as they relate to climate change

- amount of resources provided to developing country Parties, including financing for technical assistance (TA) and investment projects

- amount of finance leveraged

- sustainability of funded projects.

Established several years before the Paris Declaration, the GEF principles have to date focused mainly on supply-side effectiveness as opposed to enhanced donor-partner co-operation. ${ }^{6}$ While the principles do highlight key areas important to effectiveness, they do not provide guidance on how these can be applied or monitored in practice.

The Adaptation Fund, which was established in 2001 and adopted its strategic guidelines in 2008, takes the Paris Declaration principles into account, as well as broad benefits of the activity. For example, the Board's assessment of proposals is to take national strategies and co-benefits into account. A greater emphasis is also placed on monitoring and evaluation (AF, 2011a), drawing on DAC guidance.

Effectiveness is also specifically mentioned in the mandate of the Green Climate Fund (GCF). In particular, the Fund is to "operate in a transparent and accountable manner guided by efficiency and effectiveness" (UNFCCC, 2011). Moreover, the Board of the GCF is tasked "to develop a transparent noobjection procedure... to provide for effective direct and indirect public and private-sector financing..." (UNFCCC, 2012f). Further, monitoring and evaluation under the GCF will include "a results measurement framework with guidelines and appropriate performance indicators” (GCF, 2011). The benefits and challenges of developing results frameworks to assess the effectiveness of climate finance interventions are outlined in Box 1.

\footnotetext{
${ }^{6}$ This issue is being discussed in the context of the $5^{\text {th }}$ review of the financial mechanism.
} 


\section{Box 1: Results frameworks}

There are significant benefits to funders and implementers of climate activities of developing results frameworks. In particular, a results framework explicitly outlines for an activity: what is expected to be achieved by an activity, what the milestones are, and potentially also the underlying critical assumptions needed for the activity to be successful (IEG, 2012). Developing and using a results framework can therefore help to improve the planning and management of an intervention - and therefore its effectiveness.

However, there are challenges in establishing results frameworks. Firstly, developing and agreeing on them takes time and resources. Secondly, there is a wide variety of different types of climate responses and contexts in which they take place. This means that results frameworks for different activities will need to be tailored to their specific circumstances, and may encompass a wide range of different indicators. However, developing indicators that are e.g. specific, measurable and achievable by an intervention is not necessarily a straightforward task (César et al., 2013). Further, developing an appropriate number of indicators is also challenging: for example, Germany has developed 103 indicators for national monitoring and evaluation of its adaptation activities (OECD, 2013). In addition, some results may be difficult to quantify, and/or difficult to attribute to a specific intervention. Nevertheless, increased compatibility of different results frameworks could help to improve comparisons of the effectiveness and efficiency of different climate finance interventions.

At its June 2013 meeting, the GCF identified options for indicators of effectiveness, and also highlighted that "selection of performance indicators must be seen as an iterative process" (GCF 2013). The indicator options presented focus on the mitigation or adaptation benefits of GCF activities - at project, programme or "transformative" level. It has yet to be decided if indicators that identify co-benefits such as health improvements, reduced local air pollution, increased enterprise creation and poverty reduction are to be included (GCF, 2013).

Different UNFCCC texts have also outlined the importance of climate finance effectiveness. For example, Article 3.3 of the Convention indicates that "policies and measures to deal with climate change should be cost-effective” (UNFCCC, 1992). More recently, decision 1/CP.18 (UNFCCC, 2012a) decides to "improve the effectiveness" of finance related to reducing emissions from deforestation and forest degradation (REDD+) activities and also highlights that the work programme on long-term finance aims to inform Parties "in enhancing their enabling environments and policy frameworks to facilitate the mobilisation and effective deployment of climate finance in developing countries” (UNFCCC, 2012a).

\subsubsection{Private sector stakeholders}

Climate financing involves a range of private sector actors. While there is no one single viewpoint of this heterogeneous group, there have been a number of ad-hoc platforms that have focused on issues relevant to the effectiveness of climate financing.

For example, the Equator Principles apply to large infrastructure and industrial projects (individual projects with project finance over USD 10 million). ${ }^{7}$ These principles have been adopted by 79 financial

\footnotetext{
${ }^{7}$ The Principles include: reviewing and categorising projects based on the magnitude of its potential environmental and social risks and impacts; undertaking environmental impact assessments and developing environmental and social
} 
institutions to date, who account for $70 \%$ of project finance in emerging markets (Equator Principles, 2011). These principles are designed to determine, assess and manage social and environmental risks and negative impacts at the project level. One of the issues assessed under these principles is the "viability of project operations in view of reasonably foreseeable changing weather patterns/climatic conditions, together with adaptation opportunities” (Equator Principles, 2013).

While not focused directly on improving climate finance effectiveness, the Equator Principles try to avoid negative impacts of projects at the project-design stage. However, applying these principles will nevertheless have an impact on effectiveness. This is because they help the financial institutions determine whether projects are climate-resilient. For example, whether projects such as hydropower plants (mitigation-related) or coastal infrastructure development (adaptation-related) will be able to function as planned given expected ranges of rainfall, sea-level rise, etc. during the lifetime of the project. The ability (or inability) of these projects to continue functioning as planned irrespective of climate variability will affect whether they can meet their stated objectives.

Separately, the IIGCC has developed domestic and international policy recommendations for governments wishing to attract private sector investment in climate-resilient activities. In particular, the "Global Investor Statement on Climate Change" (IIGCC, 2011) outlines the elements of "investment-grade climate and energy policy" necessary to attract large-scale investment, focusing on the clean energy sector. The IIGCC has 285 signatories, who represent assets of more than USD 20 trillion.

These recommendations include issues such as the importance of a carbon price and the use of markets and transparency on climate-related risks. They also highlight the importance of being aligned with broader policy goals and broader efforts by the international community to scale up climate finance. As such, it is consistent with views of the development community that effectiveness is enhanced when individual interventions are consistent with nationally determined priorities. As the level of assets of IIGCC signatories dwarfs that covered by the climate finance commitments under the UNFCCC, moves towards greater effectiveness by IIGCC members could have a significant impact.

\subsection{Exploring climate finance effectiveness at different stages}

As illustrated in Figure 3, effectiveness can be considered at different stages of climate finance planning, delivery and/or use (explored in more detail in Section 3). For example, at the international level, greater discussions and co-ordination between development donors and partners can help align different actors behind common objectives. Similarly, enhancing national and sub-national institutions and enabling environments can help improve the ability of countries and organisations to allocate and absorb climate finance in an effective manner. Further, designing interventions and assessing results during the monitoring and evaluating (M\&E) stage can help improve the effectiveness with which climate finance is allocated.

management systems (which will be independently assessed) for projects with significant or limited adverse environmental and social risks or impacts; monitoring and publicising environmental information from projects. 


\section{Figure 3. Considering effectiveness at different stages}

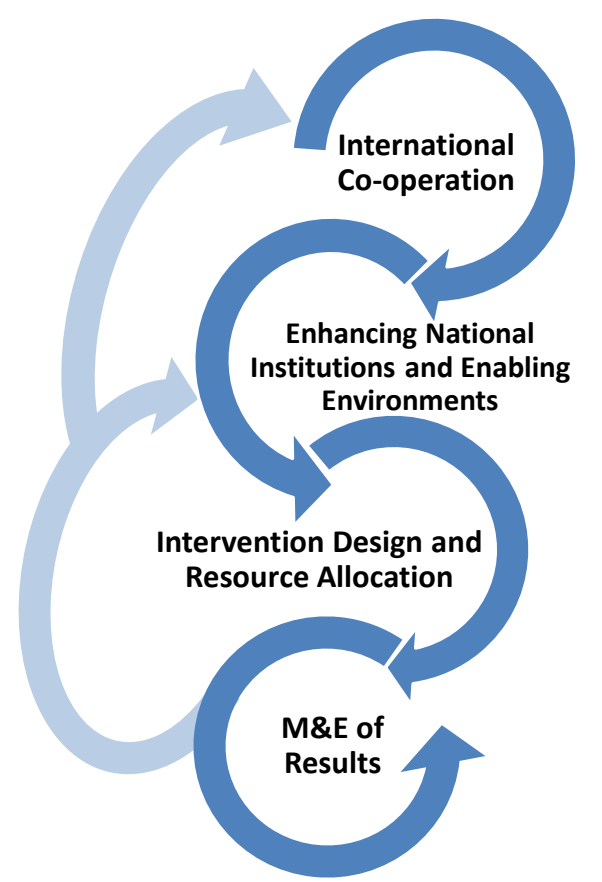

- Aligning and co-ordinating with partners and across donors

- Enhancing readiness; increasing access and absorptive capacity; strengthening country systems, institutions and enabling environments

- Designing interventions; delivering and allocating resources

- Monitoring and evaluating results; learning from experience

Stakeholders within different communities have focused on what effectiveness means during one or more of these stages. Some organisations focus on institutional and process-oriented issues such as delivery (e.g. Bird et al., 2013), access (e.g. Thornton, n.d.) absorptive capacity or "readiness" (e.g. TNC, 2012; UNDP, 2012) during more upstream stages. Some look at multiple criteria, e.g. institutions, governance, learning (Sierra et al., 2013; Brown et al., 2011).

In terms of assessing effectiveness, some financial institutions (e.g. AFD and EIB) focus on their climate finance interventions' results on the ground in terms of mitigation and adaptation, ${ }^{8}$ while others look at broader development or local environmental co-benefits (IEG, 2011). Increasingly, development finance institutions (e.g. AfDB, IDB, Islamic Development Bank, EBRD) are converging towards results frameworks that track operational, management, and project performance results under single, institutionwide systems (AfDB, n.d.).

Institutions are also beginning to integrate evaluation (e.g. AfD, 2012) and establish independent external evaluations of their projects and programmes (e.g. ICF, 2013). The DAC Evaluation Resource Centre provides a compendium of relevant evaluations from key institutions and DAC members (DeREC) ${ }^{9}$.

\section{Strengthening international and national institutions, processes, and enabling environments}

The effectiveness of climate finance is influenced by the strength of underlying international and national institutions and processes. These institutions and processes at both the international and national levels are involved in the design, delivery, mobilisation and use of climate finance. They include those of both donor and recipient countries, encompassing national and multilateral funds and implementing agencies.

\footnotetext{
${ }^{8}$ For a fuller description of activities underway in 2011-12, see Bird et al. (2012).

${ }^{9}$ DAC Evaluation Resource Centre - see: http://www.oecd.org/derec/
} 
Following the stages outlined previously in Figure 3, the subsequent sections summarise key aspects of effective institutions, processes, and enabling environments. Section 3.1 considers the role that greater alignment and co-ordination between partners and donors plays in making climate finance more effective. Section 3.2 examines the role played by country development plans, policy frameworks, and systems in accessing, mobilising, and absorbing climate finance effectively. Section 3.3 then focuses on how interventions are designed and resources allocated with a view towards maximising their effectiveness.

\subsection{International co-operation}

There are many factors that can influence the strength of international and national enabling environments and thus the ability of countries to effectively mobilise and absorb international climate finance. While the development, climate, and private sector communities agree in principle on the importance of effective enabling environments, their views on what this constitutes may differ.

For instance, the development community highlights the following pre-conditions for effective enabling environments and conditions for effective delivery of international climate finance in a recent OECD survey of 32 climate finance practitioners (Zou and Ockenden, 2013):

- mainstreaming of climate change considerations into development within national development plans and across donor activities

- improved co-ordination of actors both in-country across national ministries (allocating roles and responsibilities), and across providers and supporters

- engagement with a wide range of stakeholders; civil societies, local government, private sector, developing public-private partnerships

- strengthening of national statistical systems in recipient countries, in particular to track finance and monitor results.

These conditions are considered to reinforce and complement the aid effectiveness principles, and as climate finance specific insights to support the application of the aid effectiveness principles. It is important to highlight that these apply predominately with climate-related aid in mind. There is limited understanding of how the aid effectiveness principles relate to private climate finance mobilised through development finance - and the degree to which private climate finance mobilised by public sector efforts is accountable.

While the views of the development community and private sector are not completely aligned, they both highlight important aspects that need to be taken into account and may play complementary roles. For instance, mainstreaming climate change considerations into national development plans may involve introducing carbon-pricing mechanisms that can help to level the playing field between fossil fuel and lowcarbon investments (e.g. Morden, 2013 and GoSA, 2013).

In both the climate and development co-operation communities there is a strong emphasis on the role of country-driven policies and strategies, consistent with national development priorities, to effectively manage climate finance and take action on climate change. Capacity development (i.e. strengthening the enabling environments and national capacities to effectively manage climate finance, as well as the international co-operation and partnerships needed to support country ownership) is critical, as outlined in the Busan Partnership for Action on Climate Finance and Development Effectiveness ${ }^{10}$ (2011). Capacity is needed to support the development of national plans, strengthen national systems, identify policy priorities, specific climate mitigation and/or adaptation activities, and improve access through co-ordinated and

${ }^{10}$ See Annex A for further details on the Busan Partnership. 
complementary efforts. This issue has also been referred to as "climate finance readiness" (see e.g. UNDP, 2012). The GCF has explicitly recognised that "there is a strong need for capacity building” (GCF, 2013).

International strategies and efforts could play a role in enhancing effectiveness, such as by demonstrating and advancing key technologies along their learning curves and thus helping scaled-up deployment (Zou and Ockenden, 2013). In addition, multilateral and regional funds could facilitate achieving the aid effectiveness principles by providing greater donor co-ordination and reducing risks of fragmentation.

\subsection{Enhancing national institutions and enabling environments}

Strong national institutions and enabling environments are key to mobilising, absorbing, and channelling climate finance effectively. National institutions help to identify climate finance needs and prioritise its allocation. The ability and capacity of recipient governments to set a clear vision and strategies for climate change within national plans, to develop policies and programmes to access and absorb international climate funds, and to channel and manage resources, are critical factors in determining the effectiveness of climate finance.

\subsubsection{Enhancing national enabling environments for mobilising private finance}

The scale of investment needed to meet low-emissions, climate-resilient development pathways is likely to be far larger than the available public climate finance. Private climate finance is expected to play an important role, both in the context of the USD 100 bn climate finance commitment, as well as more broadly, whilst also presenting an opportunity for the private sector and investors.

For private finance to flow, investments need to be commercially viable. Thus, the key requirement is to strike the right balance between investors' appetite for risk and reward. Effectively mobilising private investments to finance climate-friendly and/or climate resilient activities therefore requires establishing enabling environments and domestic investment conditions that incentivise and align investment opportunities with the need for climate finance.

Public interventions can help to establish investment environments that facilitate climate-friendly investment. Such public interventions are most effective in mobilising finance when they target specific market failures and barriers that hinder investment. Analysis of the factors needed for effective national enabling environments has highlighted a number of barriers to effectively scaling-up the levels of private investment in climate-resilient activities (e.g. Corfee-Morlot et al. 2012; Gomez, 2013; Mani, 2012). These include:

- a lack of bankable, low-carbon and climate-resilient investment opportunities

- insufficient returns for climate-friendly investments when compared to other alternatives (this is partly due to the continuation of fossil-fuel subsidies, as well as the lack of carbon pricing in many areas)

- higher risks for climate-friendly investments (e.g. due to policy uncertainty, technology risk)

- availability of long-term capital (climate-friendly investments may often entail higher up-front costs and longer pay-back times)

- uncertainty in how policies are applied.

To effectively mobilise private funds, a co-ordinated approach with public and private sectors actors working together is critical to identify the role for public support and to develop targeted interventions. The private sector has identified several policy recommendations for improving national enabling environments for mobilising and attracting low-carbon investment (see e.g. IIGCC, 2011). These include the development of comprehensive, coherent policies, as well as a stable policy environment and wellfunctioning institutions (IIGCC, 2011; Mani, 2012). 


\subsubsection{Enhancing national institutional capacity and country systems, readiness and implementation}

Mainstreaming climate change into development planning has been widely recognised as an important precondition to effective development and climate finance (e.g. IPCC, 2007; OECD, 2009; UNEP, 2011). Developing an agreed national strategic vision and systematic response to climate change across government and within national plans encourages donors of international climate finance to respond to "demand-driven" country priorities. This facilitates the ability of countries to meet aid effectiveness principles. For example, donors can only meet the Paris Declaration principles of aligning climate finance behind domestic objectives and ownership if national strategies, plans, and priorities have been developed. Many developing countries (e.g. Brazil, India, Indonesia, Kenya) have established such strategies and plans, but they are not yet place in all countries benefitting from international climate finance.

Many developing countries are now integrating national climate change strategies into their medium-term national development plans. For example, as outlined in Zou and Ockenden (2013) the Colombian National Institutional Strategy for Climate Change mainstreams climate change through four priority sectoral public policies, ${ }^{11}$ each being developed and led by a different ministry; the Kenyan National Climate Change Action Plan 2013-2017 identifies six big win opportunities ${ }^{12}$ for climate finance with adaptation and mitigation co-benefits (GoK, 2012b).

International climate finance has, in some instances, been used to help develop national plans/strategies. For example, the mandate of the Least Developed Countries Fund (LDCF) is to help Least Developed Countries (LDCs) develop their National Adaptation Programmes of Action. Moreover, capacity support to develop national planning and budgetary tools can help improve the governance and efficiency of climate finance at the national level, such as Climate Change Public Expenditure and Institutional Reviews (CPEIRs - see Box 2) which build on and seek to reinforce existing government monitoring systems to integrate climate change considerations.

\section{Box 2: Climate Public Expenditures and Institutional Reviews (CPEIRs)}

UNDP have worked with and supported several countries in undertaking Climate Public Expenditure and Institutional Reviews (CPEIR). CPEIRs are a tool to provide a comprehensive overview of governments' activities related to climate change. By improving the understanding of what climate finance is, and tracking its flows, it can help countries integrate and mainstream climate change considerations into fiscal policy, expenditure planning and programming and to align national climate policies with development policies and budgets. The information and analysis from CPIERs can also provide a useful basis for a more open and transparent discussion on climate-related activities and finance. To date, CPEIRs have been carried out in Bangladesh, Cambodia, Nepal, Thailand, Samoa and Indonesia. Further studies are underway in Africa and Latin America.

For further information see: http://www.aideffectiveness.org/ClimateChangeFinance\#

In-country co-ordination mechanisms to better channel climate funds - either through budgetary mainstreaming or through separate national funds - are also emerging. These help meet aid effectiveness principles. For example in Vietnam, the Support Programme to Respond to Climate Change is a multi-

12 These are 1) geothermal power generation; 2) distributed clean energy solutions; 3) improved water resources management, 4) restoration of forests; 5) climate-smart agriculture and agroforestry; 6) infrastructure. 
donor partnership that focuses on helping the government of Vietnam develop effective institutional and policy responses. One of the specific aims of this partnership is to increase donor harmonisation (JICA, 2011); The Bangladesh Climate Change Resilience Fund was established so that development partners could support Bangladesh in implementing its Climate Change Strategy and Action Plan (BCCRF, 2013). In contrast, in countries where there is no integrated national climate change action plan or domestic climate change policy framework, it has been observed that donors are more likely to finance their own priorities (see e.g. Cameron 2011; Zou and Ockenden, 2013). This is reported to be the case even when national climate change policy reports exist i.e. NAMAs or NAPAs ${ }^{13}$ have been submitted to the UNFCCC, but it is not clear if this is a case of poor alignment or if systems are not in place to support these plans.

There are some elements of the aid effectiveness principles that are difficult to implement in practice for climate finance. For example, the use of country systems and procedures (such as national arrangements and procedures of public financial management, accounting, auditing, procurement, monitoring and evaluation) is encouraged, where appropriate (i.e. Busan 2011, and Manila Consensus 2011), to improve the effectiveness climate finance through reinforcing the sustainability of results and allowing recipient countries to take greater ownership. Practitioners recognise aid effectiveness principles and the benefits of using country systems (e.g. EC, 2008; GCCA, 2012). However, in the case of climate finance, there is recognition that progress in using country systems is limited (for example the 2011 Manila Consensus). Channelling climate finance through these systems requires sufficient local capacity in accounting, financial reporting and monitoring systems. Where these systems are weak, donors are dis-incentivised from using them, instead creating parallel systems that can be duplicative, increase transaction costs and hamper efforts to achieve country ownership and sustainable results (OECD, 2012). Furthermore, there are additional reasons why donors may prefer not to use country systems, such as the ability to account for taxpayer funds and the need to track climate-related results (OECD, 2011a).

The national and international institutions used to channel climate finance can also influence the transaction costs for developing countries in accessing, channelling and using international climate finance. As transaction costs reduce the total amount of climate finance devoted to climate activities, reducing them can increase the effectiveness of climate finance. The performance/existence of specific national institutions can also affect whether a country meets the safeguards introduced by selected climate funds to limit potential negative impacts (e.g. social) of climate interventions, or to ensure that specific standards (e.g. fiduciary standards) have been met. These issues are explored in more detail in Annex B.

\subsection{Intervention design and resource allocation}

Identifying and designing the most effective interventions, allocating resources, and managing and maturing a pipeline of projects that can absorb funds are essential components of effective climate finance. However, there are several related challenges at both the national and international level.

Allocation procedures are used by both national and international sources of climate finance and can cover a number of criteria, reflecting a range of strategic objectives that will influence the intended results of a project. These include criteria on parameters such as target countries, activity type, and project size. For example, in terms of eligible activities, the Indonesian government has identified a number of primary and secondary priorities in both mitigation and adaptation for expenditure under the Indonesian Climate Change Trust Fund (ICCTF, 2012). In terms of project size, some funds limit the total flows to a specific activity - for example, the PPCR can provide USD 3-15 million to individual projects (CIF, 2013).

\footnotetext{
${ }^{13}$ Nationally Appropriate Mitigation Action (NAMA) and National Adaptation Programmes of Action (NAPA).
} 
In terms of allocation between countries, some public or private/public funds may have explicit allocation criteria. For example, the GEF now uses a "system for the transparent allocation of resources" (STAR) to allocate funds under GEF-5 (earlier funding rounds used different allocation methods). The STAR uses transparent indicators of country performance and potential to determine indicative envelopes of resources to eligible countries. Some countries also have explicit criteria or ranges for their bilateral climate aid (e.g. SDC, n.d.).

There are many tools available in theory to support strategy development and ex-ante assessments of an intervention's effectiveness. These include marginal abatement cost curve analysis, options analysis, impact assessments, cost-benefit analysis, and multi-criteria analysis. However, information and data constraints can limit their application. In particular, limited evidence and knowledge to provide good appraisals and identify market failures and barriers as well as inherent uncertainties in appraising climate adaptation projects are cited as key barriers to identifying effective projects ex-ante.

Providers and supporters of climate finance are, however, developing methodologies to measure benefits and trade-offs among different dimensions of an intervention's impacts (e.g. environmental, social, economic, financial). Such methodologies can help to direct allocation of future climate finance to projects and programmes with the highest overall results (for example, the UK's DFID/DECC Greenhouse Gas Appraisal Guidance and the World Bank Source Book).

A project's design may include the development of a results framework against which a programme or project's effectiveness is subsequently assessed. In some instances, the design and/or financing of a project may be explicitly based on the achievement of key results. This is the case for results-based finance (see Box 3), or in the development of investment criteria for funds (for example the Climate Investment Funds Criteria for the Clean Technology Fund). 


\section{Box 3: Results-based finance}

With increasing focus on demonstrating verified results from climate projects, results-based finance (RBF) has received significant attention in the climate finance community. Results-based finance is an umbrella term that includes a number of different financing mechanisms that seek to tie the provision of financial resources to specific and measurable results (Caruso and Ellis, 2013). These range from Advanced Market Commitments and Output Based Aid that focus on "outputs" to Conditional Cash Transfers or Cash on Delivery Aid that can be linked to behavioural triggers more oriented towards “outcomes” (GPOBA, 2012).

As depicted in the figure below, payments under an RBF arrangement are only disbursed after independently verified results have been demonstrated. Depending on project types, the results chosen to trigger payments can vary widely after consultation with donors, implementing entities, and partner countries. Drawing from a number of existing or proposed RBF programmes relevant to climate change, these triggers can include the number of natural gas connections made or solar-home systems installed (GPOBA, 2013), the number of technical assistance sessions held (IFC, 2012a), or the amount of fugitive methane emissions abated (MFSG, 2013).

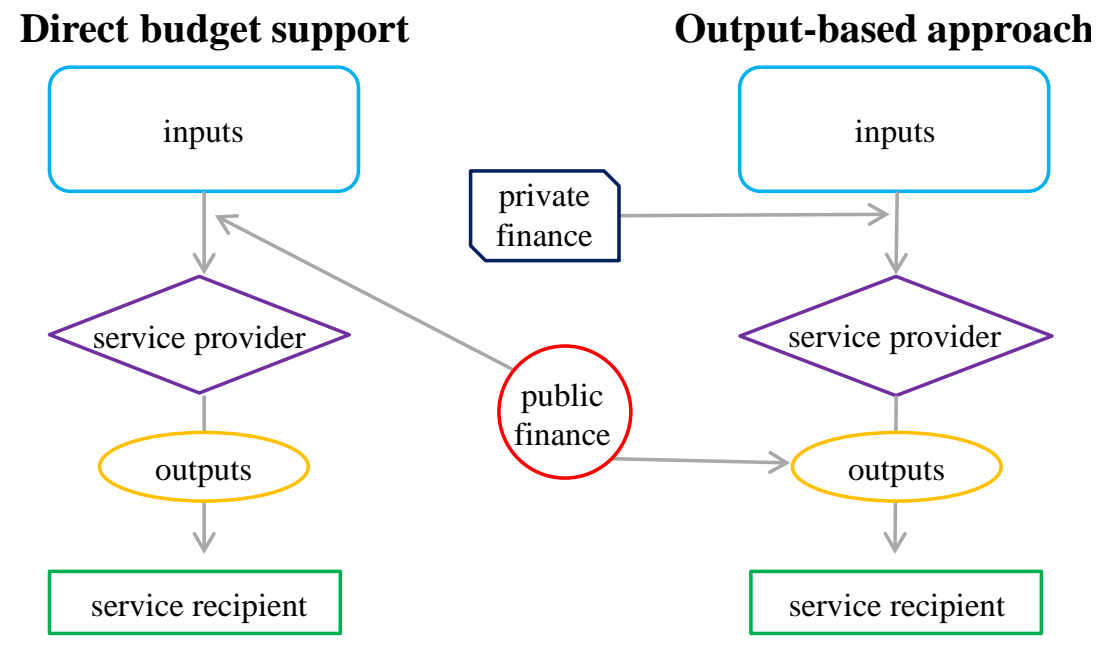

Source: Adapted from Brook and Petrie (2001)

In the context of assessing the effectiveness of climate finance projects, RBF arrangements are relevant in two ways. The first relates to the requirement of demonstrating verified results up-front. With an ex-ante assessment of mutually agreed outputs or outcomes, donors can more easily account for results to both taxpayers at home and development partners abroad. The second is how RBF approaches transfer risk from donors to service providers, thus creating a direct incentive to achieve the result more efficiently and effectively (World Bank, 2013a). However, RBF may not be appropriate in all situations, and will need to be explored further in order to understand how it best fits with the principles in the Paris Declaration and objectives of the UNFCCC.

\section{Monitoring and evaluating results of interventions}

In assessing climate finance effectiveness, it is useful to draw a distinction between what is necessary to create an enabling environment to achieve results versus what is sufficient for demonstrating that an intervention has actually achieved those results. Thus, while the enabling environments discussed in 
section 3 are critical, they are not necessarily sufficient to demonstrate the climate impacts of specific interventions.

Monitoring and evaluating (M\&E) climate finance interventions is important for a number of reasons. Identifying results of an intervention is important for transparency in both donor and recipient contexts, as well as in demonstrating the feasibility and success of projects in the context of attracting private finance. Understanding both the climate-specific and broader environmental, economic and development impacts of climate finance can facilitate a more robust assessment of the costs and benefits of more ambitious actions. Assessing effectiveness includes not only demonstrating results, but also building an evidence base of what, how, and why an intervention worked in order to inform better policies and interventions in the future.

This section outlines a conceptual framework for monitoring the results of climate finance interventions over different scales and time horizons and highlights selected indicators used across different institutions. Recognising that different climate interventions will involve a range of objectives, the selected indicators are categorised as being oriented towards mobilisation of resources, climate-specific results, and broader development benefits. ${ }^{14}$ The section then concludes by highlighting some key issues, their implications, and emerging options and tools for assessing the results of climate interventions.

\subsection{Conceptual framework for monitoring results of interventions}

The choice of time horizon and scale for monitoring results can influence assessments of an intervention's effectiveness. For example, the effectiveness of an intervention designed to improve the climate-resilience of infrastructure so that it can withstand a 1-in-100-year event may only be able to be determined after a significant time lag. There may also be a significant time lag between interventions such as capacity building, training, education, and the their effects. Further, a pilot project for a new technology may be implemented and run efficiently (and could therefore be judged to be effective at a project level), but does not meet its goal of being replicated at scale (and is therefore less effective when viewed from a national or sectoral level).

As highlighted below in Figure 4, an early stage of the implementation of an intervention involves the identification and allocation of inputs. The inputs to an intervention can be financial, human (e.g. information or labour), or material goods that help to achieve the strategic objectives of the intervention. Decisions on appropriate inputs will depend both on the strategic objectives of the intervention as well as local context and needs. For instance, a technology transfer project might not be successful in itself in the absence of local knowledge on how to utilise and maintain the technology. In such cases, financial or inkind support for appropriate capacity building activities might be complementary inputs to an intervention.

The inputs to an intervention can have different types of results: outputs, outcomes and impacts. While these terms are defined in Box 4 and outlined below, they are not always easy to apply in practice. For instance, an "output" to one institution may be considered an "outcome" by another.

Outputs are the products that are delivered by an intervention in the short-term. Monitoring the outputs of an activity demonstrates that progress has been made in implementing the activity. Outputs of climaterelated activities are generally tangible, and could include e.g. wind turbines installed, number of trees planted, km of sea-wall constructed, or training activities held.

\footnotetext{
${ }^{14}$ Alternative ways of assessing effectiveness could be to examine the impact of an intervention on progress towards the principles outlined in the Paris Declaration (although it is not clear to what extent these principles apply to private climate finance mobilised by public finance), or on the three pillars of sustainable development.
} 


\section{Figure 4. Conceptual framework for monitoring results of interventions}

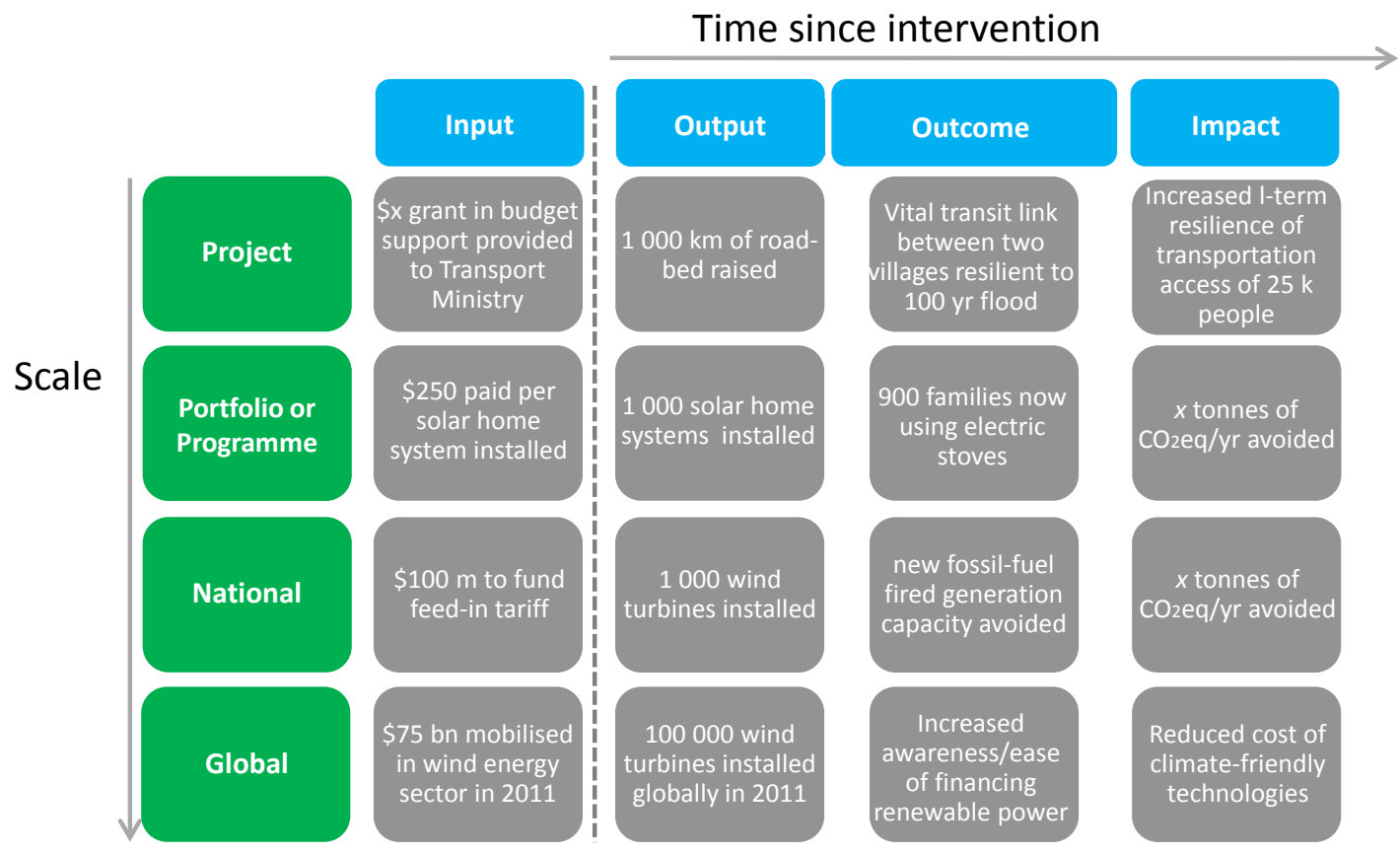

\section{Box 4: OECD key terms in results-evaluation}

- Goal: the higher-order objective to which a development intervention is intended to contribute

- Inputs: the financial, human, and material resources used for the development intervention

- Results: the output, outcome or impact (intended or unintended, positive and/or negative) of a development intervention

- Output: the products, capital goods and services that result from a development intervention; may also include changes resulting from the intervention that are relevant to the achievement of outcomes

- Outcome: the likely or achieved short-term and medium-term effects of an intervention's outputs

- Impact: positive and negative, primary and secondary long-term effects produced by a development intervention, directly or indirectly, intended or unintended

- Efficiency: outputs, qualitative and quantitative, in relation to the inputs

- Effectiveness: measure of the extent to which an aid activity attains its objectives.

Source: OECD (2002), Glossary of Key Terms in Evaluation and Results Based Management.

The outcome resulting from these outputs can occur in the short- or medium-term. For example, an outcome from training on how to deal with water shortages could be an improved ability to maintain food production under variable climatic conditions. Due to difficulty in linking specific interventions to outcomes and impacts, the outcome of an activity may be fully or partly attributable to an activity.

In contrast, impacts can be intended or unintended, occur in different sectors, and take a longer time to assess (OECD, 1991). For example, if climate-resilient infrastructure has been built to withstand a 1-in100 -year event (e.g. flooding), the effectiveness of this infrastructure in achieving its aim can only be assessed after such an event has happened. According to an intervention's objectives, desired impacts can be climate-specific (e.g. GHG reductions, improved resilience to climate change) and/or broader (e.g. 
changes to biodiversity levels, public health, or access to water). Thus, both climate-specific as well as broader development-related indicators may need to be monitored to assess effectiveness.

The issue of scale is also an important dimension in relation to how to monitor, aggregate and assess effectiveness. As climate change can have impacts at local, national and global scales, it is useful to have indicators in place to monitor the results of actions across all of these different scales. For instance, indicators such as the number of climate vulnerability assessments conducted may be important for monitoring the efficiency of delivering project-level outputs. However, it may be difficult to interpret in the absence of indicators at greater scale, such as the overall number of people vulnerable in a country. Thus, a mix of both top-down and bottom-up systems and indicators allows policy makers to better understand effectiveness by contextualising the progress of discrete interventions in contributing to transformational climate goals at global and national scales (e.g. Martins, 2013; Duarte, 2013).

However, different types of interventions (e.g. capacity building, infrastructure, regulatory or policy measures) may be more or less amenable to evaluation at these varying spatial scales and time horizons. For example, it is easier to estimate the impacts of low-carbon infrastructure projects on emissions than it is to measure the impact of a technical assistance or outreach activity on community resilience. In the latter case, it might be more practical to measure results at the output or outcome level (e.g. number of projectmanagement training sessions held or number of awareness workshops held in vulnerable communities).

\subsection{Monitoring the mobilisation of resources}

Considering the scale of both financing and low-carbon technologies that is needed to address climate change, mobilising external resources is often a strategic objective of an intervention or fund. The extent to which an intervention mobilises external resources could therefore be one upstream measure of effectiveness. Some development partners and institutions utilise results indicators for tracking resource mobilisation as part of larger monitoring and evaluation (M\&E) systems (e.g. CIF, UK, USAID, and CIFCTF), as shown below in Table 1.

One aspect of resource mobilisation relates to how much external financing an intervention is able to mobilise from public and/or private sources. Mobilising external finance can be a particularly important result for climate finance interventions that provide seed capital to private-equity umbrella funds or insurance and guarantee instruments, for example. However, the ability of an intervention to mobilise or leverage financing does not necessarily imply effectiveness in a broader sense. For instance, some analysis has highlighted the possibility that high leverage or mobilisation rates may indicate a strong perception of commercial viability amongst private investors who may have invested without public intervention (Stadelmann et al., 2011). In addition to its narrow focus, one of the difficulties in using financial mobilisation as an indicator in assessing effectiveness is that there are wide differences in how mobilisation and leverage are defined and measured between different institutions (see Caruso and Ellis, 2013 for a more detailed discussion). Even in the absence of methodological differences, mobilisation rates will vary significantly across financial instruments, technologies, sectors, and countries (UN AGF, 2010; Smallridge, et al., 2012; Ellis and Regan, 2012).

Another type of resource mobilisation may be the transfer and scaling up of low-carbon or climateresilience technologies to developing countries. Given the variety of technologies, sectors, and scales of technology-transfer interventions, it would be difficult to have a single meaningful indicator that could be aggregated across multiple projects. For instance, the Global Environment Facility's (GEF) indicator for technology-transfer interventions is qualitative in nature, focusing on capturing the type and maturity of technologies that are being transferred. 
Table 1. Examples of indicators for mobilising inputs

\begin{tabular}{|c|c|c|c|c|}
\hline Indicator & Units & Result type & Selected users & Type \\
\hline \multicolumn{5}{|c|}{ Project, Portfolio, National and/or Global Level Indicators } \\
\hline $\begin{array}{l}\text { Amount of private } \\
\text { finance (mobilised) }\end{array}$ & \multirow[t]{2}{*}{ Unit of currency } & \multirow{3}{*}{$\begin{array}{l}\text { Output - } \\
\text { Outcome }\end{array}$} & \multirow{2}{*}{$\begin{array}{l}\text { UK-ICF; US; CIF; } \\
\text { GEEREF; GEF }\end{array}$} & \multirow[t]{2}{*}{ Quantitative } \\
\hline $\begin{array}{l}\text { Amount of (external) } \\
\text { public finance } \\
\text { (mobilised) }\end{array}$ & & & & \\
\hline $\begin{array}{c}\text { Transfer of innovative } \\
\text { technologies }\end{array}$ & Types and status & & GEF & Qualitative \\
\hline
\end{tabular}

Source: UK, 2013; USG, 2012; CIF, 2013; Arnould, 2013; and GEF, 2011b

\subsection{Monitoring climate-specific results}

The climate-specific results of mitigation and adaptation interventions are core to assessing their effectiveness and are a distinguishing characteristic of climate finance as compared to broader development finance. Mitigation-focused interventions generally seek to reduce GHG emissions directly (e.g. by improving fuel combustion efficiencies) or indirectly and/or in the longer-term (e.g. by increasing awareness about low-GHG technologies). Projects seeking to increase adaptive capacity and resilience can take a number of forms (e.g. awareness and education programmes, institutional reforms, physical infrastructure projects) and have results that accrue at local, regional, or global scales and over different time horizons.

While mitigation and adaptation activities are addressed separately in this section, there can be significant overlap between these two themes in practice. Recent OECD-DAC data show that $21 \%$ of climate-related ODA flows address both mitigation and adaptation, reflecting the multiple objectives of donors' interventions (OECD, 2013c). A more concrete understanding of the specific results from such projects could also serve to better highlight the synergies or trade-offs that exist between mitigation and adaptation.

\subsubsection{Mitigation activities}

In the case of mitigation activities, a core element of effectiveness will be the impact the intervention has on the Earth's climate system. Table 2 presents a number of example indicators in use across governments (in developed and developing countries) and institutions for monitoring the performance of mitigation activities. The table organises indicators into two groups:

- indicators used to monitor progress at global and national scales, e.g. emissions intensity (per GDP or unit of energy), ratio of renewables to fossil fuels in total energy supply, or net change in GHG emissions

- intervention-level indicators used to monitor achievements of discrete activities (which can then be aggregated upwards to portfolio, national, or global scales), e.g. installed renewable energy capacity, hectares of deforestation avoided or number of low-carbon technologies supported. 
In practice, most efforts towards assessing the climate-impacts of mitigation interventions focus on emissions of GHGs at the project or portfolio level, often converted into units of $\mathrm{CO}_{2}$ equivalence $\left(\mathrm{CO}_{2}-\right.$ eq). To this end, a group of nine international financial institutions (IFIs) ${ }^{15}$ have been working towards a harmonised approach for accounting for GHG impacts of their project portfolios (World Bank, 2012). For example, the Carbon Footprint tool of the Agence Française de Développement's (AFD) can be used to conduct an ex-ante evaluation of the GHG impacts of proposed projects in a variety of sectors, measured in units of $\mathrm{CO}_{2}$-eq (AFD, 2010). This enables AFD to track the climate impacts of AFD's investments at the portfolio-level. It also allows potential climate impacts to be considered when making decisions on project design and ultimately funding for all projects and not just "climate” projects. (For specific institution level guidelines, see e.g. IFC, 2013; EIB, 2012; GEF, 2011b; EBRD, 2010; OPIC, 2009.)

To a lesser extent, some institutions do include non-GHG indicators in their overall monitoring systems. These broader indicators include MW of renewable energy capacity installed, lifetime or annual GWh of energy saved, as well as hectares of deforestation and afforestation (e.g. SE4ALL, 2013; UK, 2013; IDB, 2012; CIF, 2012a, 2012c, 2011; GEF, 2011b; AfDB, n.d.). Some institutions who do report on these other activities also providing modelling estimates for those activities' $\mathrm{CO}_{2}$ impacts, (e.g. CIF, 2011 and GEF, 2011b). Additionally, a number of institutions include indicators on policies implemented or capacity building activities held (e.g. USG, 2012; IDB, 2012; KfW, 2011; and GoP, n.d.). While these interventions may not lead directly to GHG reductions, increasing technical knowledge and capacity can help facilitate enhanced mitigation actions subsequently.

However, the scale of climate change, and the possibility of "leakage" (e.g. displacing emissions from one place to another) necessitates a broader understanding of emissions and trends beyond a simple aggregation of project- or portfolio-level results. To this end, some institutions adopt a more top-down approach by assessing effectiveness at sectoral, national, or even global scales.

At the national scale, a number of developing countries are already in the process of designing monitoring and evaluation systems for in-country mitigation activities. For example, South Africa is establishing a Climate Change Response Measurement and Evaluation System, which is designed for, inter alia, "impact assessment of climate finance flows..." and assisting South Africa in meeting international reporting requirements for developing countries (Morden, 2013). Both the Philippines and Bangladesh have developed indicators for climate interventions, the former as part of an overarching results framework for its 5-year development plan and the latter as part of its national climate change fund (Philippines, 2011 and BCCRF, 2010). The Republic of Mozambique is also in the early stages of building a comprehensive M\&E framework for climate change activities implemented by public, private, and non-governmental organisations (Manjate, 2013). The Government of Kenya (GoK) is in the process of setting up what it calls an MRV+ system, which combines the elements of project-level M\&E in a coherent framework that facilitates meeting international MRV guidelines (GoK, 2012a). These actions highlight the importance that developing countries also attach to understanding how effective international financial commitments are in achieving low-carbon, climate-resilient development goals at the national level.

Some international funds and institutions also utilise indicators to track results at national and global scales. For example, in line with its strategic objective of financing transformational shifts towards lowcarbon economies, the Climate Investment Funds' (CIF) Clean Technology Fund (CTF) includes the amount of GHGs produced per unit of GDP as a national-level performance indicator (CIF, 2012). The CIF tracks this metric over time and compares progress to the baseline year determined by when the countryspecific investment plan was established. At both national and global scales, the International Energy Agency's (IEA) Energy Sector Carbon Intensity Index (ESCII) tracks the amount of $\mathrm{CO}_{2}$ emissions

\footnotetext{
${ }^{15}$ ADB, AFD, EBRD, EIB, IDB, IFC, KfW, NEFCO, and WB.
} 
produced per unit of energy supplied in selected countries and regions (IEA, 2013). In order to put these changes into context, the IEA calculates ESCII pathways consistent with two, four, and six-degree climate scenarios. This type of metric allows for overall progress in decarbonising the energy sector to be tracked over time.

These types of initiatives provide the tools for investors, donors, and recipient countries to more fully appreciate the expected climate-related impacts of interventions across different spatial scales and time horizons. However, the larger the scale of assessment (and the longer the time horizon for assessment), the more difficult and uncertain it becomes to attribute an outcome or impact to a specific intervention. When coupled with ex-post evaluation and later compared to the intended objectives of a project, such information can form a useful evidence base for evaluating effectiveness.

Table 2. Examples of indicators for mitigation activities

\begin{tabular}{|c|c|c|c|c|}
\hline Indicator & Units & Result type & Selected users & Type \\
\hline \multicolumn{5}{|c|}{ National and Global Level Indicators } \\
\hline Total Emissions & $\mathrm{tCO}_{2 \mathrm{eq}}$ & Impact & IEA; UNFCCC & \multirow{5}{*}{ Quantitative } \\
\hline $\begin{array}{c}\text { Total Emissions } \\
\text { (per capita) }\end{array}$ & $\begin{array}{l}\mathrm{tCO}_{2 \mathrm{eq}} \\
\text { person }^{-1}\end{array}$ & \multirow{3}{*}{$\begin{array}{l}\text { Outcome - } \\
\text { Impact }\end{array}$} & WB & \\
\hline $\begin{array}{l}\text { Emissions intensity } \\
\text { (per unit of energy) }\end{array}$ & $\mathrm{tCO}_{2 \mathrm{eq}} \mathrm{kWh}^{-}$ & & WB; IEA & \\
\hline $\begin{array}{c}\text { Emissions intensity (per } \\
\text { unit GDP) }\end{array}$ & $\begin{array}{c}\mathrm{tCO}_{\text {2eq }} \text { unit } \\
\mathrm{GDP}^{-1} \\
\end{array}$ & & IEA; IDB; China; US & \\
\hline $\begin{array}{c}\text { Ratio of power } \\
\text { generation capacity from } \\
\text { low-carbon sources }\end{array}$ & $\%$ & Outcome & IDB; Colombia & \\
\hline \multicolumn{5}{|c|}{ Project and Portfolio Level Indicators } \\
\hline $\begin{array}{l}\text { Number of relevant } \\
\text { policies or capacity } \\
\text { building activities }\end{array}$ & $\begin{array}{l}\text { Absolute } \\
\text { number }\end{array}$ & Output & IDB; Philippines; KfW & \multirow{6}{*}{ Quantitative } \\
\hline Avoided $\mathrm{CO}_{2}$ emissions & $\mathrm{tCO}_{2 \text { eq }} \mathrm{yr}^{-1}$ & Impact & $\begin{array}{l}\text { UK-ICF; AFD, AfDB; } \\
\text { USAID; CIF-FIP|CTF; } \\
\text { GEF; JICA; Indonesia- } \\
\text { ICCTF; Zambia }\end{array}$ & \\
\hline $\begin{array}{c}\text { Sequestered } \mathrm{CO}_{2} \text { through } \\
\text { forestry activities }\end{array}$ & $\mathrm{tCO}_{2 \mathrm{eq}}$ & & CIF-FIP; GEF & \\
\hline $\begin{array}{l}\text { Installed renewables } \\
\text { capacity }\end{array}$ & MW & Output & $\begin{array}{l}\text { UK-ICF; CIF-CTF; } \\
\text { GEF; IDB; AfDB; } \\
\text { USAID } \\
\end{array}$ & \\
\hline Energy savings & GWh $\mathrm{yr}^{1-}$ & \multirow[b]{2}{*}{ Outcome } & CIF-CTF; GEF & \\
\hline $\begin{array}{c}\text { Avoided deforestation or } \\
\text { improved land } \\
\text { management }\end{array}$ & Hectares & & $\begin{array}{l}\text { UK-ICF; USAID; IDB; } \\
\text { SIDA; AfDB; BNDES; } \\
\text { Indonesia-ICCTF }\end{array}$ & \\
\hline
\end{tabular}

Source: IEA, 2012; UNFCCC, 2012b; World Bank, 2013b; Briner, 2013, pers. comm.; IDB, 2012; USG, 2012; GoP, n.d.; KfW, 2011; CIF, 2011; CIF, 2012a; GEF, 2011b; AfDB, n.d.; UK, 2013; César, 2013; Duarte, 2013; Martins, 2013; Mulenga, 2013.

\subsubsection{Adaptation activities}

Like mitigation, adaptation interventions can take on a number of forms, including infrastructure projects; research and development; technical assistance and capacity building; and policy, regulatory, or institutional measures. Unlike mitigation, the ultimate impacts of specific interventions (e.g. increased adaptive capacity and resilience) are difficult to model ex-ante or measure directly. While broader 
developmental impacts are often regarded as co-benefits in the context of mitigation, some of these same aspects become core indicators for the effectiveness of adaptation interventions. As shown in Table 3, this has led to the monitoring of a diverse array of indicators. Although adaptation and resilience are determined by environmental, social, and economic factors linked to sustainable development, this section focuses on indicators that are vulnerability or resilience-specific. For simplicity, other indicators relevant to adaptation will be discussed in the subsequent section on broader development benefits.

Table 3. Examples of indicators for adaptation activities

\begin{tabular}{|c|c|c|c|c|}
\hline Indicator & Units & Result type & $\begin{array}{c}\text { Selected } \\
\text { users }\end{array}$ & Type \\
\hline \multicolumn{5}{|c|}{ National and/or Global Level Indicators } \\
\hline $\begin{array}{c}\text { Number of people vulnerable to climate } \\
\text { change }\end{array}$ & Absolute number & Impact & $\begin{array}{l}\text { PPCR;AF, } \\
\text { Kenya }\end{array}$ & Quantitative \\
\hline $\begin{array}{l}\text { Integration of climate change in } \\
\text { national planning and development } \\
\text { frameworks; co-ordination of actors }\end{array}$ & NA & Outcome & $\begin{array}{l}\text { PPCR;AF; } \\
\text { AfDB; GEF; } \\
\text { SIDA ; } \\
\text { Zambia }\end{array}$ & Qualitative \\
\hline $\begin{array}{c}\text { Number of laws, policies, regulations, } \\
\text { strategies, etc. addressing climate } \\
\text { adaptation }\end{array}$ & Absolute number & $\begin{array}{l}\text { Output - } \\
\text { Outcome }\end{array}$ & $\begin{array}{l}\text { USAID; } \\
\text { AfDB; AF; } \\
\text { GEF; } \\
\text { Philippines }\end{array}$ & Quantitative \\
\hline $\begin{array}{l}\text { People permanently displaced due to } \\
\text { climate change }\end{array}$ & $\begin{array}{l}\text { Absolute number } \\
\text { or } \% \text { of } \\
\text { population } \\
\end{array}$ & Outcome & SIDA; Kenya & Quantitative \\
\hline \multicolumn{5}{|c|}{ Project and Portfolio Level Indicators } \\
\hline $\begin{array}{l}\text { Number of people targeted by } \\
\text { intervention }\end{array}$ & Absolute number & \multirow{3}{*}{ Output } & $\begin{array}{l}\text { UK- } \\
\text { ICF;PPCR; } \\
\text { Zambia }\end{array}$ & \multirow{5}{*}{ Quantitative } \\
\hline $\begin{array}{l}\text { Number of climate vulnerability } \\
\text { assessments conducted }\end{array}$ & Absolute number & & $\begin{array}{l}\text { USAID;AF; } \\
\text { GEF }\end{array}$ & \\
\hline Outreach and CB efforts & $\begin{array}{l}\text { Person hours; } \\
\text { absolute number } \\
\text { of fora }\end{array}$ & & $\begin{array}{l}\text { USAID; } \\
\text { AfDB; AF; } \\
\text { Kenya; IDB }\end{array}$ & \\
\hline $\begin{array}{l}\text { Number of institutions with improved } \\
\text { capacity to address climate change }\end{array}$ & Absolute number & \multirow{2}{*}{$\begin{array}{l}\text { Outcome- } \\
\text { Impact }\end{array}$} & $\begin{array}{l}\text { USAID; } \\
\text { AfDB; AF; } \\
\text { Zambia }\end{array}$ & \\
\hline $\begin{array}{l}\text { Physical infrastructure and assets } \\
\text { improved or strengthened }\end{array}$ & $\begin{array}{l}\text { km of road; } \\
\text { absolute number }\end{array}$ & & $\begin{array}{l}\text { USAID; } \\
\text { AfDB; AF; } \\
\text { Kenya; } \\
\text { Philippines }\end{array}$ & \\
\hline $\begin{array}{l}\text { Increased capacity to adapt to impacts } \\
\text { of climate change }\end{array}$ & $\begin{array}{l}\text { Absolute number } \\
\text { or qualitative }\end{array}$ & $\begin{array}{l}\text { Outcome- } \\
\text { Impact }\end{array}$ & $\begin{array}{c}\text { UK- } \\
\text { ICF;USAID; } \\
\text { AF; PPCR; } \\
\text { SIDA; } \\
\text { Zambia } \\
\end{array}$ & $\begin{array}{l}\text { Quantitative or } \\
\text { Qualitative }\end{array}$ \\
\hline $\begin{array}{l}\text { Development and testing of climate } \\
\text { response instruments }\end{array}$ & NA & Outcome & $\begin{array}{l}\text { PPCR; } \\
\text { Zambia }\end{array}$ & Qualitative \\
\hline
\end{tabular}

Source: CIF, 2012b; AF, 2011a; GoK, 2012b; GEF, 2012; GoP, n.d.; César, 2013; UK, 2013; USG, 2012; IDB, 2012 ; Mulenga, 2013.

In practice, the difficulty of assessing resilience and adaptive capacity has often resulted in climateadaptation monitoring efforts focusing on institutional and procedural output indicators as opposed to outcomes and impacts (e.g. IEG, 2013; Lamhauge et al., 2012). An OECD analysis of over 100 adaptation projects and programmes of six bilateral development agencies found that the majority of monitoring 
activities concentrated on policy and administrative management; education; research; and co-ordination aspects as opposed to risk-reduction (Lamhauge et al., 2012).

For adaptation interventions, linking outputs or outcomes to larger scale impacts on resilience can be even more difficult than in the case of mitigation. This is due to the multi-faceted nature of building resilience and adaptive capacity, which often requires cross-cutting interventions in the health, water, energy, economic, agriculture, and other sectors. The absence of clear links between cause and effect in many adaptation activities highlights the utility of using both top-down (e.g. number of people vulnerable to climate change in a country) and bottom-up indicators (e.g. number of climate vulnerability assessments conducted).

For example, the Adaptation Fund tracks a number of indicators to evaluate results at the output, outcome, and long-term impact stages at both the project and programme scales. The Fund's choice of indicators depends on the intended goals of different projects. For instance, an indicator to evaluate the effectiveness of an education and awareness project may report the "number and type of risk reduction actions or strategies introduces at local level" or "number of news outlets in the local press and media that have covered the topic" (AF, 2011a). To assess the effectiveness of projects in reducing longer-term vulnerability, the Fund tracks headline numbers such as "number of people with reduced risk to extreme weather events."

As climate-financing interventions often have multiple objectives, labelling projects with adaptationspecific goals as solely an "adaptation project" can be an oversimplification. Thus, adaptation interventions often use results frameworks that contain indicators that are relevant to broader development objectives.

\subsection{Monitoring broader development benefits}

As outlined in Section 2, the breadth of desired results will vary across different actors and funds relevant to climate finance. While some sources of climate finance have a narrow focus, e.g. specifically on climate impacts, others are much broader. Efforts to mainstream climate change issues into development activities, and vice versa, are growing. Thus, there is a growing need for climate interventions to demonstrate their impact on development and for development activities to show their impact on the climate system. As financial needs for both development and climate activities currently exceed supply, this further underscores the importance of managing projects for multiple objectives and demonstrating results. Capturing these broader benefits in concrete terms can also build a case for more ambitious, scaled-up actions.

A number of institutions attempt to capture these broader benefits by incorporating relevant indicators in their results frameworks (see Annex $\mathrm{C}$ for further discussion and institution-specific examples). These include indicators on:

- biodiversity and local environmental quality (e.g. proportion of marine area protected, forest loss, or species richness)

- access to energy and transport (e.g. number of additional people benefitting from access to renewable energy or low carbon transport)

- water resources and food security (e.g. access to reliable and safe water, desertification of crop fields, dependence on food aid)

- health and sanitation (e.g. infection rates of climate-sensitive diseases, number of health measures or sanitation facilities introduced)

- livelihood and socio-economic impacts (e.g. income diversification, jobs created, or traditional livelihoods preserved). 
Efforts towards progress in some areas are often intentionally mainstreamed in other climate-relevant indicators rather than being evaluated individually. This includes issues such as reducing disproportionate social and environmental impacts on women or indigenous populations. For instance, many institutions include guidance to disaggregate results by gender or impacts on indigenous peoples, where appropriate (UK, 2013; Mulenga, 2013; CIF, 2011, 2012a, 2012c; GEF, 2012). This approach allows policy makers to understand more concretely the broader development impacts of an intervention.

\subsection{Key methodological issues in assessing effectiveness}

An understanding of the indicators that institutions use to monitor the effectiveness of their interventions is a useful starting point. Nevertheless, there are a number of key issues and challenges to consider when evaluating these results and tracking effectiveness.

This section outlines some issues and concepts that are useful in understanding the pros and cons of different approaches to monitoring results and evaluating effectiveness. This section also explores a number of definitional and methodological challenges that hamper the ability to track results over the spatial scales and time horizons often desired.

\subsubsection{Setting baselines and choosing goals}

Assessing the effectiveness of an intervention in achieving its goals often requires defining a baseline or target against which to gauge progress. The process of choosing a hypothetical scenario ("counterfactual”), a core principle of impact evaluation, can be technically difficult, data-intensive and subject to significant uncertainties (see e.g. Clapp and Prag, 2012). Without meaningful baselines or counterfactuals, however, it is difficult to assess the causal relationship between the observed impacts and the goals of a specific intervention.

In practice, the process of defining goals and indicators needs to balance the need for specificity with the resource implications needed to monitor at more disaggregated or granular levels. This is especially relevant for indicators used to compare interventions or that are aggregated for tracking and reporting at larger scales, since data collected using dissimilar or vague indicators may not be comparable.

Baselines can be needed at both the national and project scale. However, the subjective nature of establishing baselines means that choices of baselines can vary widely (see e.g. Clapp et al., 2009). At a project or portfolio scale, analysis has highlighted that estimated emissions reductions can vary by a factor of three for renewable energy and more than a factor of ten for energy efficiency projects across different MDBs carbon foot-printing tools (Bossard, 2012, pers. comm.). The wide variation in assumptions and models to establish baselines will lead to wide differences in the estimated results of an intervention when compared to that baseline. This variation decreases comparability, hinders aggregation, and will in turn influence assessments of effectiveness. The choice of a baseline is particularly difficult for adaptation interventions. This is because uncertainty surrounding the future effects of climate change can result in the baseline "shifting" over time, which further complicates assessing impacts (see Lamhauge et al., 2012).

\subsubsection{Assessing a "transformational change" or "paradigm shift"}

Large step-changes are needed in emission levels, financial flows, technologies, institutions, and behaviours in order to move to a low-emissions, climate-resilient pathway consistent with limiting global temperature rises to less than two degrees Celsius. A number of institutions and climate funds have outlined the need for a "transformational change" or "paradigm shift" (GCF, 2013) as part of their core mandates and objectives. However, these concepts are often vague or undefined. Nevertheless, assessing whether an intervention has been effective at delivering such transformational change will require an ability to monitor progress in these areas. In general, transformational changes typically involve longerterm, scaled-up impacts. While overall trends may be able to be observed at these scales and time horizons, 
assessing and attributing the effectiveness of a discrete intervention in causing the observed impact is inherently more difficult (as illustrated by Figure 5).

Attribution can be particularly difficult for adaptation interventions. For example, while the output of a capacity building exercise on the impact of climate change on agricultural productivity can be identified relatively easily (e.g. $x$ number of people trained), identifying the outcome of this activity (e.g. droughtresistant crops planted on $y$ hectares of land) is more difficult to identify. The impacts of such an activity (e.g. improved food security) will be even more difficult to attribute, given time lags, natural variability in weather patterns, "shifting" baselines due to the effects of climate change, and interactions with outcomes/impacts from other related interventions. While assessing the effectiveness of an intervention in producing project-level outputs is relatively straightforward, attributing long-term, global impacts to an intervention is extremely challenging.

Figure 5. Difficulty of attributing impacts to discrete interventions

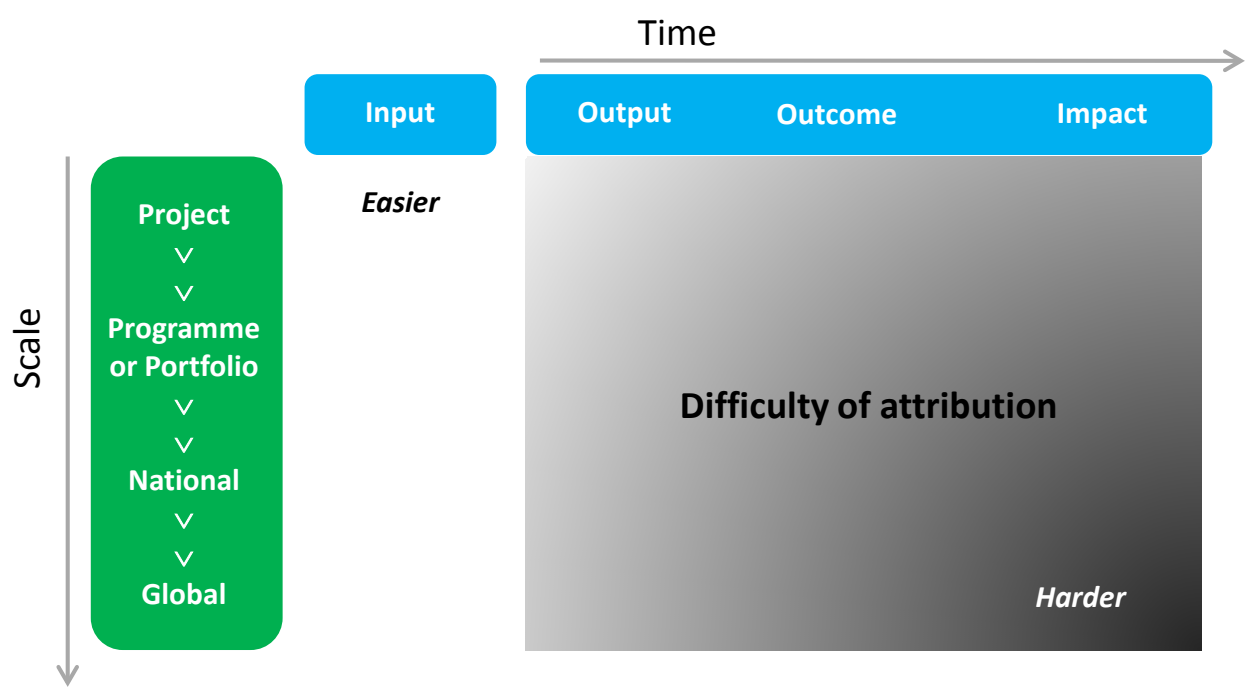

This difficulty in determining attribution has led some in the M\&E community to use the word "contribution" as opposed to "attribution" when discussing the relationship between a discrete intervention and longer-term impacts (e.g. AfDB, n.d.; Lamhauge, 2013, pers. comm.). The reason for these difficulties is primarily the multitude of other factors that come into play over greater spatial scales and time horizons, a problem particularly acute for funds whose objectives are longer-term, transformational impacts.

The issue of causality and attribution also exists in the context of resource mobilisation and technology demonstration, as both require an understanding of whether or how they individually contribute to largerscale impacts. For example, some funds' objectives are focussed on bringing down the costs of low-carbon technologies, demonstrating their technological or financial viability, or introducing them into new markets (e.g. CIF, 2012a). These programmes or funds focus on transforming the economics of low-carbon technologies at different scales, with a view towards transformational shifts in investment patterns from carbon-intensive production and consumption to low-carbon, climate-resilient investments. Progress in these areas may be relatively easy to measure (e.g. levelised cost of electricity for different technologies as in UNEP, 2013), but will be difficult to attribute to specific interventions or policies owing to time-lag issues, uncertainty and difficulties in determining causality over time.

Looking more broadly, some institutions may also be assessing the shift from "brown" to "green" investments. For instance, the IEA's Tracking Clean Energy Progress report provides an assessment of whether current global investment levels, technology costs, and renewable energy generation are consistent 
with the financing and infrastructure needs of a two-degree scenario (IEA, 2013). By annualising the needs for longer-term impacts, this type of analysis overcomes the time lag that complicates evaluating the effectiveness of today's interventions in achieving future global climate goals.

This time lag issue can be less of a problem in the context of certain types of mitigation projects where the GHG impacts can be estimated or measured, noting the uncertainties of these estimations discussed previously. However, certain types of mitigation interventions such as technical assistance, capacity building, or policy and regulatory reforms will still be difficult to relate to impacts.

Assessing transformational shifts may require that both positive and negative impacts of interventions be monitored and tracked. This would allow for the net impact of an intervention as well as possible trade-offs between the different elements of effectiveness to be evaluated. However, most of the results frameworks examined in this paper frame indicators in gross terms (i.e. only positive impacts) as opposed to net terms (i.e. positive minus negative impacts) and lack guidance for capturing negative impacts. Notable exceptions include GHG foot-printing tools that are applied at the portfolio level (including both "brown" and "green" projects) by some financial institutions (e.g. AFD) or national level indicators that track headline trends in vulnerability or GHG emissions, which inherently reflect positive and negative impacts.

\subsubsection{Effect of intervention context on results}

Results from similar intervention types may vary depending on when and where the intervention occurs, even in the absence of methodological or definitional differences between indicators used across institutions. Such context-specificity means that the same input will not achieve the same result (e.g. outputs, outcome, or impact) in all cases. This is because certain results can be influenced by socioeconomic conditions and geography that reflect national and local circumstances. For example, levels of private finance catalysed by an intervention may vary according to the country's investment framework, investment risk and enabling environment. At a project level, prevailing wind speed/insolation will determine how much wind/solar electricity is produced by a specific renewable energy system; composition of household waste will influence the maximum levels of landfill gas production, which will affect how much can be captured/flared.

Stakeholders will need to decide what level of comparability or aggregation in effectiveness is desirable, keeping in mind that for some interventions, lower results for a given input could still represent equivalent effort or progress. Performance between interventions could differ due to existing policy frameworks and enabling environments or national circumstances such as geographic remoteness and limited intervention sizes (e.g. in Small Island Developing States (SIDS)) that can inhibit achieving economies of scale. For instance, certain interventions intended to prove the viability of specific technologies in given circumstances or penetrate new markets might lead to lower short-term climate benefits for the same financial input directed towards established technologies, but could still be effective over longer time horizons beyond the lifetime of the project itself. Similarly, interventions designed to meet multiple aims (e.g. increased forest sequestration, increased biodiversity, improved local livelihoods - which may be achieved by agro-forestry or mixed plantations) may not maximise results for an individual aim (e.g. increased sequestration by forests - which may be achieved by monoculture plantations).

\subsubsection{Cost-effectiveness and value for money}

Cost-effectiveness and value for money are of paramount importance for donors accountable to taxpayers and developing countries looking to maximise the results of available inputs. Cost-effectiveness (efficiency) is often identified quantitatively: that is, results compared to inputs. On the other hand, value for money can consider additional information, such as the broader development impacts of an intervention or the role the intervention is likely to play in developing or proving a new technology. 
In the context of addressing climate change most effectively, each of these concepts has its applications. For instance, in the mitigation context, an ex-ante assessment of cost-effectiveness - typically summarised by marginal abatement cost, or costs per tonne of carbon abated metrics - may allow a fund manager to allocate scarce resources efficiently according to a least-cost abatement strategy. However, costeffectiveness metrics might not be equally well suited for other types of interventions, such as a financial interventions intended to improve the risk-return profile to attract private finance by taking a first-loss position in an investment fund. These types of activities may prove to be cost-effective in the long-run, but would not perform well in ex-ante evaluations where their benefits are not well captured by models.

Furthermore, the cost-effectiveness approach might be difficult to apply to certain types of interventions. This includes interventions that increase a country's capacity to mitigate or adapt to climate change, or that improve the enabling environment for climate responses within the country. Cost-effectiveness could also disadvantage certain types of interventions (e.g. small-scale energy-efficiency) or countries (e.g. SIDS), where transaction costs would be relatively higher. Using cost-effectiveness to assess the effectiveness of climate finance more broadly could lead to perverse incentives to channel financing to regions with lower transaction costs as opposed to greater need. These concerns underlie calls from developing countries for "needs-based" as opposed to "results-based" financing in the UNFCCC negotiations (e.g. LMDC, 2013 and remarks by the Philippines in IISD, 2013).

Further, cost-effectiveness calculations can skew assessments of effectiveness if not all costs and/or benefits of an intervention are monetised. Focusing only on cost-effectiveness could also lead to the concentration of financing into regions that could attract financing at market-rate terms, which could lead to crowding-out as opposed to mobilising and crowding-in private capital. The broader concept of value for money is inherently subjective (e.g. whose values apply?), context-specific, and not amenable to comparison across projects.

\subsubsection{Complexity of underlying financial instruments}

A number of issues related to tracking climate finance flows are also relevant for tracking effectiveness. At a basic level, being able to assess and track the effectiveness of climate finance interventions assumes that the climate finance associated with these interventions is itself being tracked in a comprehensive manner, which is not always the case (e.g. see Clapp et al., 2012).

Further, the unique structure of certain climate finance instruments such as private equity fund-of-funds or de-risking instruments such as insurance and guarantees can complicate assessing their effectiveness. This is because it may be difficult to ensure the collection of project-level information from the ultimate beneficiary of these funds (Caruso and Ellis, 2013).

\subsection{Emerging options and tools for assessing effectiveness}

One area of growing interest within impact evaluations in the development community is that of fieldbased experimentation and randomised control trials (RCTs) (Banerjee and Duflo, n.d.). Such methods seek to test whether theories of change are leading to observable results and can help to overcome some of the challenges outlined with regards to causality, baselines and attribution. The design of RCTs (explained more fully in Duflo et. al, 2006) seeks to establish an external counterfactual. This allows a given policy or programme to be judged against the performance of randomly selected, similar, and actual cases that have not been subject to the intervention as opposed to assumed baselines of how the intervention's subjects would have performed in its absence.

RCTs can be a useful tool in exploring causal relationships between interventions and impacts at the micro scale. However, as they focus on local as opposed to global causation factors (Deaton and Banerjee, 2012) they may lack external validity at larger scales and in other contexts (Pritchett and Sandefur, 2013). 
In addition, a number of econometric-based methods exist to facilitate a better understanding of effectiveness at the macro scale. Such methodologies, for instance, allow for a characterisation of contextual effects in enhancing or supressing the effectiveness of an intervention, e.g. the influence that national programmes or policies such as feed-in tariffs have on an intervention's ability to mobilise private capital (Cardenas et al., forthcoming). Such methods may be better suited to assessing the effectiveness of policies and measures.

\subsection{Learning and knowledge management}

One of the key objectives of monitoring and evaluating the effectiveness of climate change interventions is to improve the design and implementation of future policies and activities. To this end, a number of stakeholders have or are in the process of designing systems and strategies to collect data and synthesise lessons learned. These efforts include multilateral initiatives such as the Adaptation Learning Mechanism ${ }^{16}$, the World Bank's Climate Change Knowledge Platform; Busan Partnership's regional knowledge sharing platforms; work by Civil Society Organisations such as the Climate and Development Knowledge Network; and efforts within developing countries such as Kenya's planned knowledge exchange platform (GoK, 2012b).

These efforts involve two distinct elements of knowledge management: sharing data and sharing lessons. The former allows for project designers and evaluators to access baseline or contextual data efficiently while the latter involves making the results of M\&E efforts widely available to those contemplating or designing similar interventions. Sharing data is a relatively easy task, provided that such information is readily available or able to be scaled to the required level. A number of factors, however, can complicate sharing lessons both within and between organisations. These include lack of formal co-ordination and advanced planning, uncertainty on how to organise information in a useful format, and difficulties in making context-specific findings relevant to other interventions (e.g. see previous discussion on RCTs).

With lesson sharing as an often-cited objective of interventions, more attention could be placed during M\&E activities on how this was achieved in practice, especially for pilot-type projects where little information exists. For instance, an independent review of the CIFs highlighted that the incorporation of information sharing and lesson learning in interventions varied significantly by fund (ICF, 2013). The report found that lesson learning in CTF mitigation-interventions was "weak to non-existent," slightly stronger performance for their adaptation activities, and mixed performance for their forestry and pilot programmes.

\section{Initial insights and possible way forward}

Demand for climate finance in developing countries is expected to exceed the USD 100 bn per year by 2020 that developed countries have committed to mobilise. It is therefore important to maximise the impact and effectiveness of climate finance. However, much of the focus to date has been on tracking the quantity of climate finance flows rather than the quality, or effectiveness, of this finance.

In order to achieve the scale required, the provision and implementation of climate finance will need to involve different communities. These include those working on development and climate issues, as well as the private sector. Each of these communities has their own views on important issues for climate finance, some of which have been laid out as principles relating to climate finance effectiveness. These views and principles are often at the institutional, national or international level. They cover some, although not all, of

\footnotetext{
16 The Adaptation Learning Mechanisms is sponsored by GEF, UNDP, WB, UNFCCC, UNEP, and FAO, with participation from a number of civil society organisations and bilateral donors.
} 
the multitude of public and private actors in developed and developing countries that will be involved in providing, channelling and/or allocating climate finance.

There is significant common ground between the different communities on issues that are important regarding climate finance. Indeed, the extent of common ground has been growing over time, as the climate community has integrated principles agreed in the development community (e.g. via the Paris Declaration and Busan Partnership) and vice versa (e.g. on the importance of transparency). For example, all three communities agree that scaled-up climate finance is needed, that both public and private sources can play a key role, and that the (self-) sustainability of a project and transparency is important. However, different communities may naturally place greater emphasis on different aspects of effectiveness. For example, meeting the urgent and immediate adaptation needs of climate-vulnerable countries will be important to the development and climate communities, but not necessarily a priority of private investors. There may also be differences of emphasis within an individual community, particularly the private sector.

For instance, the climate community has adopted a number of relevant texts outlining important issues relating to climate finance within the context of the UNFCCC. Sometimes, this is explicitly referred to as "effectiveness", e.g. in the context of the Global Environment Facility and the Green Climate Fund. Sometimes, it is not explicitly referred to as effectiveness, e.g. in the context of achieving a balance between climate finance for mitigation and adaptation in the Fast Start Finance period. Within the development community, more than 150 countries (as well as IFIs and other international organisations) agreed the Busan Partnership on Effective Development Co-operation in 2011. This declaration applies to development finance (i.e. broader than the previously-agreed Paris Declaration on Aid Effectiveness, which just covers ODA), The Busan Partnership focuses on increased co-operation between donor and partner countries and their institutions involved in providing, channelling and using climate finance - and aligning interventions with partners' priorities. Further, some within the private sector have adopted certain principles or environmental and social safeguards (e.g. IIGCC statement and Equator Principles) that are relevant to climate finance. However, the key requirement of the private sector for effective investment generally involves maximising risk-adjusted financial returns.

It is as yet unclear to what extent agreements from the development community, such as the Paris Declaration principles and Busan Partnership, also apply to or influence private climate finance that is mobilised by development finance. In addition, the aims of different sources of climate finance interventions are also affected by the channels through which they flow. For example, some climate funds focus on adaptation, some on mitigation, some on specific geographical regions. This means that it would be challenging to distil a common definition of climate finance effectiveness.

Many climate interventions are managed for multiple aims and objectives. For example, climate finance that is also ODA is required, by definition, to promote the economic development and welfare of developing countries (as well as leading to climate benefits). Thus, existing approaches and frameworks in use to assess effectiveness at the level of specific interventions are often multi-dimensional. The range of objectives of different sources and channels of climate finance can also influence assessments of climate finance effectiveness. This is because managing the results of an intervention to meet multiple goals (e.g. carbon sequestration, improved local livelihoods, increased biodiversity) may lead to different choices in allocating climate finance to specific intervention types and/or locations than managing an intervention to maximise an individual goal (e.g. carbon sequestration). As such, there are a variety of issues and methodological challenges that need to be considered for monitoring, evaluating and tracking effectiveness. In addition, assessments of effectiveness can vary according to the different approaches adopted within a given community.

The issue of what climate effectiveness is will be determined by the aims of a specific intervention, and will also be influenced by the source and channel of climate finance. In other words, whether a particular 
use of climate finance is assessed as effective depends on the type and breadth of objectives it is compared against.

Additionally, where views on effectiveness are assessed along the chain of climate finance planning, delivery and use is also crucial. For example, at the international level, greater discussions and coordination between development donors and partners can help align different actors behind common aims/objectives. Similarly, strengthening national and sub-national institutions and enabling environments can help improve the ability of countries and organisations to allocate and absorb climate finance in an effective manner. Further, designing interventions and assessing results during the monitoring and evaluating (M\&E) stage can help improve the effectiveness with which climate finance is used. These different stages can be complementary. For instance, international co-operation and capacity building to create strong national institutions and statistical systems can help to facilitate better intervention-level M\&E. Likewise, lessons learned from robust M\&E can inform international co-operation efforts to allocate financing to intervention models that have proven successful and to reform those that have not.

How climate finance results are assessed will also influence assessments of effectiveness. In particular, effectiveness will be influenced by the:

- Context within which an intervention occurs: This includes national, institutional and local/sitespecific issues. At the national level, it is difficult for donors to meet the aid effectiveness principle of aligning their inputs with country priorities if a developing country has not yet established such priorities or strategies. At the institutional level, varying national circumstances or enabling environments can enhance or inhibit an intervention's success. Site-specific environmental factors can also influence the performance of an intervention (e.g. a wind turbine will generate varying amounts of electricity depending on the prevailing wind speed).

- Time horizon of the assessment: Some climate interventions can give rise to immediate results (e.g. energy efficiency projects). However, some interventions will lead to results that either materialise or can only be assessed after a longer time (e.g. constructing infrastructure that can withstand a 1-in-100-year flood). Also, the performance of an intervention might not be static over time; results measured after 1 year or after 20 years could differ significantly. These different timescales of results mean that effectiveness levels will vary depending on when effectiveness is assessed. Choosing an appropriate point in time for assessment can be particularly complicated for climate finance interventions aimed at long-term transformational impacts.

- Scale at which effectiveness is assessed: In accordance with its aims, an intervention may seek results at the project, national, or international scale, which will have implications for how its effectiveness is assessed. For example, an intervention that seeks transformational change in a given sector may be judged effective at the project-level if it produces the expected outputs (e.g. off-grid renewable electricity, number of people trained in drought-resistant agriculture). However, if the intervention's is not replicated at scale, the transformational impacts of the intervention will be limited.

\section{Conflicts and trade-offs exist}

Considering the diversity of views and objectives across communities, there are a variety of conflicts and trade-offs that exist in assessing climate finance effectiveness. These include:

- Accommodating different aims of different actors in a single intervention. Climate finance programmes and projects can involve multiple actors, each with different views and objectives relating to climate finance effectiveness. Whilst for some interventions, the principles that apply 
may be clear i.e. the aid effectiveness principles for climate-related ODA, it may be less clear for other interventions.

- Demonstrating immediate results vs. transformational change. There is increased pressure on public providers of climate finance in developed countries to demonstrate the results achieved in developing countries with this finance. It is generally more straightforward to identify and attribute short-term outputs to an activity than their longer-term outcome or transformational impact. It may also be more straightforward to identify and attribute results at the project or programme level, rather than more broadly at national or global scales. Such a focus on concrete projects and programmes and their results risks skewing funding decisions to discrete activities with more immediately-quantifiable results rather than investing in enabling activities or activities that are mainstreamed into broader development plans and could have greater longer-term impacts. Focusing on a narrow range of results could also risk skewing funding to activities that focus solely on climate, rather than other, benefits. The choice of the breadth and detail of indicators will also have important implications for cost and the level of aggregation possible.

- Better integrating climate finance into development finance statistics. In accordance with existing international agreements, developed countries will want to account for finance they provide for climate responses in developing countries. This would imply earmarking specific funding for a specific purpose. In contrast, lessons from the development community indicate that general budget support is a more effective modality for delivering aid. However, as general budget support is not earmarked, the proportion of it spent on climate activities is not always counted as "climate finance" ${ }^{17}$ and incentives are not in place.

- $\quad$ Judicious use of scarce public financial resources. Projects with high leverage rates could indicate effectiveness. Alternatively, they could point to financially attractive projects that may have been implemented without inputs of international public finance. This would limit the additionality of climate finance and could potentially mean public climate finance displacing (crowding out) the private sector. Similarly, targeting climate finance on negative or low-cost mitigation activities, such as energy-efficiency measures, could crowd out the private sector unless the intervention is targeted at overcoming specific market failures.

- Identifying lessons learned. Identifying lessons learned is a key aspect of public climate finance interventions, and much effort has gone into identifying these lessons. An enhanced understanding of what works and why can help to scale up certain types of interventions and/or flows, which is particularly relevant for pilot or innovative approaches. Sharing lessons-learned is important both within and across institutions. It is unclear to what extent private suppliers of climate finance are prepared to publicly share their lessons learned.

Assessing results, as well as identifying effective modalities for delivering climate finance, can be an iterative process and involve making trade-offs in areas such as those outlined above.

\section{Way forward for assessing effectiveness}

In spite of these different views and challenges, several stakeholders active in the climate finance field have developed criteria and/or frameworks to help identify elements of effectiveness for their various

\footnotetext{
17 Within the OECD CRS system, Rio markers to track ODA commitments targeting climate-related objectives cannot be applied to general budget support given this spend cannot be earmarked or tracked.
} 
interventions. These results frameworks can help stakeholders build up a knowledge base of what has worked and what not, and can increase transparency and accountability.

Key questions for future development of effectiveness results frameworks are:

- To what extent do principles of development effectiveness (which apply to climate-related aid and other official flows) apply to or influence private climate finance mobilised by public climate finance?

- Should results frameworks used to assess the effectiveness of climate interventions focus solely on the climate results of an intervention, or also encompass broader development benefits?

- How flexible should assessment tools be (to deal not only with different types of interventions, but changing national and international priorities and frameworks over time)?

- How to further increase harmonisation of results frameworks at different scales and levels (e.g. project-level monitoring and evaluation, donor/intermediary/fund-level systems, and national development plan goals) both within the area of climate finance, and in other relevant areas (e.g. post-2015 sustainable development goals)? 


\section{Annex A: Aid Effectiveness Principles}

The Paris Declaration on Aid Effectiveness (2005) was agreed to by 137 countries and territories, as well as 28 international organisations. The Declaration outlines the following five fundamental principles for making aid more effective.

The Paris Declaration Pyramid:

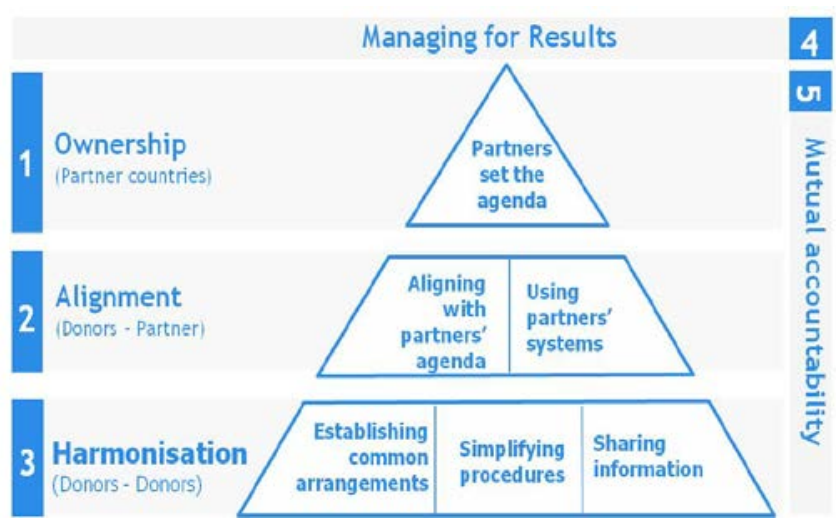

Source: OECD (2007)

The Accra Agenda for Action (AAA, 2008), reaffirms and elaborates on the Paris Declaration Commitments, emphasising the reciprocal commitments of both developed and developing countries. The AAA includes provisions on:

- Predictability - donors will provide 3-5 year forward information on their planned aid to partner countries.

- Country systems - partner country systems (i.e. in developing countries) will be used to deliver aid as the first option.

- Conditionality - donors will switch from reliance on prescriptive conditions about how and when aid money is spent to conditions based on the developing country's own development objectives.

- Untying - donors will relax restrictions that prevent developing countries from buying the goods and services they need from whomever and wherever they can get the best quality at the lowest price.

A review of progress in implementing the Paris Declaration (OECD 2012b) has however revealed only been limited progress in implementing the Paris Declaration (with only 1 of the 13 targets for 2010 being met for ODA as a whole - see OECD 2012b for a detailed discussion).

The Busan Partnership for Effective Development Co-operation - now embodied in the Global Partnership - sets out principles, commitments and actions that offer a foundation for effective co-operation in support of international development. During the Busan 4th High Level Forum on Aid Effectiveness (2011) climate finance in the context of development co-operation was outlined as a priority for effective international development. In particular, to "Continue to support national climate change policy and planning as an integral part of developing countries' overall national development plans, and ensure that where appropriate - these measures are financed, delivered and monitored through developing countries' systems in a transparent manner"18.

\footnotetext{
${ }^{18}$ 4th High Level Forum on Aid Effectiveness, 2011, para 34a
} 
The Busan Partnership for Action on Climate Finance and Development Co-operation Effectiveness is a voluntary partnership to promote coherence and collaboration across the climate and the development communities. It aims to assist donors and partner countries to apply lessons from development cooperation to the management of climate finance, focusing on supporting the development of national capacities and country systems in order to effectively allocate, manage and track domestic and international climate finance in partner countries. Under this voluntary partnership, 27 countries and institutions, including the OECD and UNDP, are working together to promote coherence and collaboration.

For further information see the official web space and information Hub for the Busan Partnership for Action on Climate Change Finance and Development Effectiveness: http://www.climatefinancedevelopmenteffectiveness.org/busan-partnership-for-action.html 


\section{Annex B: The impact of transaction costs and safeguards on effectiveness}

Transaction costs can affect the effectiveness of international climate finance. Safeguards introduced to ensure specific standards are met for international climate finance can also influence the effectiveness of this finance. These issues are discussed below.

\section{Transaction costs}

Transaction costs refer to the portion of climate finance that is used for managing and/or accessing climate finance. Aside from reducing the total amount of climate finance devoted to climate activities, funds or programmes with large transaction costs will disfavour small-scale projects, e.g. that take place in small island developing states (SIDS) (Maclellan, 2011).

In terms of transaction costs related to accessing climate finance, the climate finance architecture has evolved to be a complex landscape of bilateral programmes and multilateral funds. ${ }^{19}$ Developing countries often struggle to untangle this web. Governance structures can affect the ease with which developing countries access international climate finance. Although one of the Paris Declaration principles is that donors are to align their funding with national priorities and use local systems, this has not always been implemented (see e.g. Thornton n.d.). The problem of transaction costs can be magnified in situations with multiple donors - each with their own governance and reporting structure - are involved in an individual activity.

How climate finance is accessed (i.e. which jurisdictions oversee and manage funding, implement activities) can also affect transaction costs. This is because access can affect the time lag between identifying a potential climate response and implementing it. For example, the application process by the Solomon Islands to GEF took more than two years (Maclellan, 2011). Different modalities of climate finance access have been used over the years (Box 5). Newer funds are increasingly using direct access or enhanced direct access.

\section{Box 5: Climate finance access modalities}

Multilateral access: climate fund, implementing body are at international level. Executing body is at national or international level.

Direct access: climate fund is international; implementing body and executing body are in the national domain. (i.e. financial resources can be accessed directly once a body is accredited).

Enhanced direct access: climate fund oversight is international; climate fund is managed nationally; implementing body and executing body are in the national domain.

Source: Adapted from ODI and UNEP, 2011

For example, the UNFCCC's Adaptation Fund channels funding directly to National Implementing Entities (NIEs) that meet agreed fiduciary standards. These entities can be at the national, regional or multilateral level, and can also include non-governmental actors (e.g. as in the case of the Senegalese NIE) (AF, 2011b). This can facilitate providing climate funding to a wide variety and scales of interventions

\footnotetext{
${ }^{19}$ Climate Policy Initiatives, The Landscape of Climate Finance (2012).
} 
(including local actors), which can in turn encourage a wider uptake of climate responses. The Bangladeshi Climate Change Resilience Fund (BCCRF), funded by international donors, has a management committee comprising representatives government departments (with limited donor input) which decides on funding priorities (Khan, 2012). These structures facilitate access by enabling entities in the implementing country to make the funding decisions. The GCF is also planning to allow for direct access as well as enhanced direct access.

In terms of direct transaction costs, these can be made explicit or not. For example, some funds provide information about their transaction costs, e.g. the Bangladesh BCCRF is subject to 4.3\% "programme administration and management costs" (World Bank, n.d.). The Amazon Fund, run by the Brazilian National Development Bank, has transaction costs of 3\% (Amazon Fund, 2008). Information for direct transaction costs may be more difficult to identify at the national or supra-national level, e.g. for donor countries' aid agencies and bilateral finance institutions, or for international institutions such as the GCF. Some organisations, e.g. GEF, provide estimates of in-kind contributions.

\section{Safeguards}

Safeguards are institutional screening measures established to reduce the risk of negative consequences (e.g. environmental and social impacts) and to ensure basic institutional requirements have been met (e.g. adequate financial management and anti-corruption systems). While safeguards can play an important role, they may themselves cause a barrier to accessing climate finance and can therefore inhibit its effectiveness.

Previous experiences with GEF, for instance, demonstrated that their former safeguard requirements created a "major bottleneck" in disbursing and accessing finance (GEF, 2008). For example, some countries took several years before establishing their Designated National Authority (DNA) for the CDM. As the DNA approved proposed CDM projects, delays in establishing them also delayed interest and therefore funding from potential CDM project developers.

Another commonly-used safeguard relates to transparency, i.e. availability of information on monies received and used. For example, the Amazon Fund (focused on REDD+ in Brazil) ensures full access to external auditors of its records (Amazon Fund, 2008), and the Adaptation Fund has signed up to the International Aid Transparency Initiative in April 2013 (IATI, 2013). 


\section{Annex C: Assessing broader development benefits}

A number of institutions include indicators in their results frameworks for assessing the broader development benefits of their interventions. These are grouped and further explored as follows:

\section{Biodiversity and local environmental quality}

Climate activities can also have impacts in other environmental areas, including biodiversity and local environmental quality, such as air quality. While GHG-related impacts of mitigation interventions accrue globally, the impacts necessary for climate-resilience are more directly linked to local conditions. This has led a number of institutions and funds to develop indicators to capture biodiversity and environmental cobenefits of interventions (see e.g. UK, 2013; Thamrin, 2013; CIF, 2011; and AF, 2011a).

Currently, the United Kingdom's Department for International Development (DFID) is developing a performance indicator to capture the value of ecosystem services protected by its International Climate Fund (UK DFID, 2013). In the context of adaptation, these local biodiversity and environmental impacts can be inter-linked. For example, a forestry project that decreases soil erosion may increase the local water table. In turn, more sustainable access to groundwater for agriculture can help to increase food security, a key component of adapting to a changing climate. Some institutions also track changes in forest fragmentation, ecologically important forest loss, species richness, and the proportion of terrestrial and marine area protected by climate-related interventions (e.g. IDB, 2012; CIF, 2011; and AF, 2011a).

However, in the context of mitigation, some broader environmental impacts, such as reduction of indirector non-GHG pollutants (e.g. NOx, SOx, particulate matter, ozone), were not captured in the results frameworks examined in this paper. Nevertheless, improved local air quality is an important broader impact of certain mitigation actions and programmes (e.g. Climate and Clean Air Coalition). The availability of such data could also help to support a case for scaled-up mitigation actions domestically, for example by enabling researchers to better assess the benefits of mitigation actions in addition to costs.

\section{Access to energy and transport}

Mitigation and adaptation interventions can include important social dimensions, such as providing access to low-carbon, climate-resilient transportation or improved productivity from enhanced energy access. To capture these important relationships, several institutions track output and outcome indicators relevant to transportation and energy access (e.g. the number of expected beneficiaries of a project).

Among these institutions, the World Bank's Global Partnership on Output-Based Aid (GPOBA) tracks both the number of planned and delivered outputs as well as the number of planned and actual beneficiaries, based on disbursement data. Likewise, the UN Secretary-General's Sustainable Energy for All (SE4ALL) has increased energy access as its core goal (SE4ALL, 2013). In order to track progress in meeting its objectives, SE4ALL has developed a Global Tracking Framework that tracks progress in energy access and energy efficiency changes. The CIF's “Scaling up Renewable Energy Program” in lowincome countries (SREP) also includes indicators for measuring progress towards country-defined targets in the areas of alleviating energy poverty. These include those based on the Multidimensional Energy Poverty Index and the "number of women, and men, business and community services benefiting from improved access to electricity” due to its interventions (CIF, 2012c).

Investments in low-carbon, climate-resilient transportation infrastructure can also deliver important social co-benefits, e.g. by increasing access to transportation. For instance, the CTF has as one of its core outcome indicators the "number of additional passengers (disaggregated by men and women if feasible) using low-carbon public transport as a result of CIF intervention" (CIF, 2012a). The CTF also provides a useful example of how gender considerations can be mainstreamed into existing evaluations and indicators. 
A number of other institutions capture increased access to low-carbon transportation (see e.g., IDB, 2012; GEF, 2011b; and AfDB, n.d).

\section{Water resources and food security}

Climate interventions can be linked to water and food security issues in a myriad of ways. Increased energy access can have positive impacts on access to basic services such as clean water (e.g. through desalinisation systems powered by renewable energy) and food security (e.g. through education on climateresilient agriculture or deployment of drought early-warning systems). As a result, increased and enhanced access to water can further affect communities' adaptive capacity and resilience to climate change. For adaptation, many results frameworks do contain indicators to track impacts in these areas. For example, the CIF’s "Pilot Program for Climate Resilience" (PPCR) and Republic of Kenya (Kenya) both include indicators on access to reliable and safe water (CIF, 2012b and Kenya, 2013). In the area of food security, Kenya also tracks how many hectares of productive land have been lost to soil erosion and how many households are in need of food aid as part of its national M\&E systems for assessing climate resilience and adaptive capacity (GoK, 2012b). SIDA also includes a number of indicators related to food security, starvation, and malnutrition as part of the M\&E of its adaptation programme (César et al., 2013).

In the mitigation context, a number of technologies and activities affect water quality and quantity. These include geothermal development, biofuels production, and carbon capture and storage. Each of these technologies can introduce competing demands for scarce water supplies (e.g. biofuel, geothermal production, CCS) or pose a risk of contamination of underground aquifers (e.g. CCS) (IEA, 2012, 2013 and WEF, 2008). Despite these relationships, none of the results frameworks for mitigation activities examined for this paper include indicators for their positive or negative impacts on water resources.

\section{Health and sanitation}

The relationship between climate change mitigation and adaptation activities and health and sanitation is complex and includes impacts in a number of areas already discussed (e.g. local air pollution, energy access, water and food security). In the results frameworks analysed in this paper, few contained health and sanitation specific indicators. Notable exceptions include the Adaptation Fund, GEF, and SIDA, which include indicators for infection rates of climate-sensitive diseases, the number of health measures introduced, and sanitation and wastewater facilities, respectively. (GEF, 2012; AF, 2011a; and César et al., 2013).

\section{Livelihood and socio-economic impacts}

Responses to climate change have important impacts on livelihoods and socio-economic conditions. Mitigation and adaptation interventions can create jobs, secure incomes, and reduce losses in the face of increasing extreme-weather events. Recognising the economic dimension of resilience, some institutions have developed results indicators for tracking economic vulnerability. For instance, both the GEF and Adaptation Fund include indicators to assess the effectiveness of an intervention in diversifying and strengthening livelihoods and sources of income for vulnerable populations (GEF, 2012 and AF, 2011a). Some institutions (e.g. UK-DFID’s International Climate Fund and Government of Zambia) also track direct jobs created by mitigation and adaptation interventions (UK DFID, 2013 and Mulenga, 2013).

Considering the disparate impacts climate change can have on traditional livelihoods, the CIF's Forest Investment Programme and GEF have both developed indicators to monitor the number of indigenous people able to maintain their traditional livelihoods and changes in income in agricultural or forestry communities (GEF, 2012 and CIF, 2011). 


\section{References}

ADB (2013), Establishing the Canadian Climate Fund for the Private Sector in Asia under the Clean Energy Financing Partnership Facility, http://www.adb.org/documents/establishing-canadian-climate-fund-privatesector-asia-under-cefpf.

AEP (Aid Effectiveness Portal) (2013), CPEIR Country Reports, http://www.climatefinancedevelopmenteffectiveness.org/.

AF (2011a), Results Framework and Baseline Guidance: Project Level, Adaptation Fund Board, https://www.adaptation-

fund.org/sites/default/files/Results\%20Framework\%20and\%20Baseline\%20Guidance\%20final\%20compressed. pdf.

AF (2011b), “Implementing Entities”, https://www.adaptation-fund.org/page/implementing-entities.

AFD (2010), AFD Carbon Footprint, http://www.afd.fr/lang/en/home/AFD/L-AFD-s-engage/responsabilite-socialeenvironnementale-afd/bilan-carbone.

AFD (2011), AFD and East Africa: Partnering for Regional Development (brochure), Paris, http://www.afd.fr/webdav/shared/PORTAILS/PUBLICATIONS/PLAQUETTES/AFD_Afrique_de_lEst_GB.p df.

AFD (2012), Reconciling development and the fight against climate change, Action Plan 2012-16, http://www.afd.fr/webdav/shared/PORTAILS/SECTEURS/CLIMAT/pdf/Climat_GB_HD.pdf

AFD (2013), “AFD’s Program of Green Credit Lines in China”, http://www.afd.fr/lang/en/home/pays/asie/geoasie/chine?actuCtnId=99654.

AfDB (n.d.), "Bank Group Results Measurement Framework”, http://www.afdb.org/fileadmin/uploads/afdb/Documents/Publications/Bank\%20Group\%20Results\%20Measure ment\%20Framework\%20-\%20REV\%202[1].pdf.

Amazon Fund (2008), Amazon Fund: Project Document, http:/www.amazonfund.gov.br/FundoAmazonia/export/sites/default/site_en/Galerias/Arquivos/Boletins/Amaz on_Fund_-_Project_Document_Vs_18-11-2008.pdf.

Arnould, C. (2013), personal communication with Cyrille Arnould, GEEREF, European Investment Bank, January 2013.

AusAID (2012), Australian Multilateral Assessment March 2012: Climate Investment Fund, http://www.ausaid.gov.au/partner/Documents/cifs-assessment.pdf.

Banerjee, A.V., and E. Duflo (n.d.), “The Experimental Approach to Development Economics”, Massachusetts Institute of Technology and Abdul Latif Jameel Poverty Action Lab, Cambridge, MA, http://economics.mit.edu/files/3159.

BCCRF (2013), The Bangladesh Climate Change Resilience Fund, http://bccrf-bd.org/.

Bird, N., H. Tilly, N.C. Trujillo, G. Tumushabe, B. Welham, and P. Yanda (2013), Measuring the effectiveness of public climate finance delivery at the national level, ODI; London, U. K., http://www.odi.org.uk/sites/odi.org.uk/files/odi-assets/publications-opinion-files/8303.pdf.

Bird, N., T. Beloe, J. Corfee-Morlot, and S. Zou (2012), Understanding climate change finance flows and effectiveness - mapping of recent initiatives, ODI, UNDP, CPEIR, and OECD; London, U.K., http://www.odi.org.uk/sites/odi.org.uk/files/odi-assets/publications-opinion-files/7922.pdf.

Bossard, L. (2012), personal communication with Lucas Bossard, International Finance Corporation, Climate Business Group, February 2012. 
Briner, G., (OECD) (2013), Personal communication.

Brook, P.J. and Petrie, M. (2001), Output-based aid: precedents, promises , and challenges, http://www2.gtz.de/Dokumente/oe44/ecosan/en-output-based-aid-2007.pdf.

Brown, J., B. Buchner, G. Wagner, and K. Sierra. (2011), Improving the Effectiveness of Climate Finance: A Survey of Leveraging Methodologies, http://climatepolicyinitiative.org/wp-content/uploads/2011/11/Effectiveness-ofClimate-Finance-Methodology.pdf.

Buchner, B, A. Falconer, C. Trabacchi, and J. Wilkinson (2012), Public Climate Finance: A Survey of Systems to Monitor and Evaluate Climate Finance Effectiveness, Climate Policy Initiative, http://climatepolicyinitiative.org/wp-content/uploads/2012/07/Public-Climate-Finance-Survey.pdf.

Buchner, B., J. Brown and J. Corfee-Morlot (2011), Monitoring and Tracking Long-Term Finance to Support Climate Action, OECD; Paris, http://www.oecd.org/environment/climatechange/48073739.pdf.

Cameron, C. (2011), Climate Change Financing and Aid Effectiveness: Ghana Case Study, OECD and AfDB, http://www.oecd.org/dac/environment-development/48458430.pdf.

Cardenas, M., I. Haščič, N. Johnstone, J. Silva, and A. Ferey,(forthcoming), “Inducing Private Finance for Renewable Energy Projects: Evidence from Micro-Data”, OECD Environment Working Papers, OECD, Paris.

Caruso, R. and J. Ellis (2013), "Comparing Definitions and Methods to Estimate Mobilised Climate Finance", OECD/IEA Climate Change Expert Group Papers, No. 2013/02, OECD Publishing. doi: 10.1787/5k44wj0s6fq2-en

César, E., G. Ölund Wingqvist, and S. von Walter (2013), Climate Change Adaptation Indicators, SIDA. http://sidaenvironmenthelpdesk.se/wordpress3/wp-content/uploads/2013/05/Final-Report-LFA-and-indicatoranalysis-20130410.pdf

CIF (2011), Forest Investment Program Results Framework, Climate Investment Funds, Washington, https://www.climateinvestmentfunds.org/cif/sites/climateinvestmentfunds.org/files/FIP_Results_Framework_fi nal.pdf.

CIF (2012a), Revised CTF Results Framework, Climate Investment Funds, Washington, https://www.climateinvestmentfunds.org/cif/sites/climateinvestmentfunds.org/files/Revised_CTF_Results_Fra mework.pdf.

CIF (2012b), Revised PPCR Results Framework, Climate Investment Funds, Washington, https://www.climateinvestmentfunds.org/cif/sites/climateinvestmentfunds.org/files/Revised_PPCR_Results_Fra mework.pdf.

CIF (2012c), Revised SREP Results Framework, Climate Investment Funds, Washington, https://www.climateinvestmentfunds.org/cif/sites/climateinvestmentfunds.org/files/Revised_SREP_Results_Fra mework.pdf

CIF (2013), Procedures for Allocating PPCR Resources on a Competitive Basis from an Agreed Set Aside of Resources, https://www.climateinvestmentfunds.org/cif/sites/climateinvestmentfunds.org/files/Procedures_for_Allocating_ PPCR_Resources_on_a_Competitive_Basis_from_a_Set_Aside_0.pdf.

Clapp, C., J. Ellis, J. Benn, and J. Corfee-Morlot (2012), "Tracking Climate Finance: What and How?", OECD/IEA Climate Change Expert Group Papers, No. 2012/01, OECD Publishing. http://dx.doi.org/10.1787/5k44xwtk9tvk-en.

Deaton, A. and Banerjee, A. (2012), Session III- Searching for Answers with Randomized Experiments (video), NYU Development Research Institute, New York, NY, http://www.youtube.com/watch?v=2Js-AxZcmr8.

Duarte, Mafalda (2013), “Measuring Climate Effectiveness”, African Development Bank. Presentation at the CCXG Global Forum, September, 2013, Paris, http://www.oecd.org/env/cc/2a\%2005-

2013\%20Sept\%20CCXG\%20Effectiveness\%20Duarte.pdf. 
Duflo, E., Glennerster, R. and Kremer, M. (2006), "Using Randomization in Development Economics Research: A Toolkit”, NBER Technical Working Paper Series, No. 333, National Bureau of Economic Research, Cambridge, MA, http://www.nber.org/papers/t0333.

EBRD (2010), EBRD Methodology for Assessment of Greenhouse Gas Emissions, v. 7, http://www.ebrd.com/downloads/about/sustainability/ghgguide.pdf.

EBRD (2012), Catalyzing Private Sector Climate Finance, Cape Town, South Africa, http://unfccc.int/files/cooperation_support/financial_mechanism/longterm_finance/application/pdf/josue_tanaka,_ebrd.pdf.

EIB (2012), European Investment Bank Induced GHG Footprint v. 10, EIB. http://www.eib.org/attachments/strategies/eib_project_carbon_footprint_methodologies_en.pdf

Ellis, J. and C. Regan (2012), Climate Finance: Annotated Questions Document, OECD; Paris, http://www.oecd.org/env/cc/Discussion Document_Climate Finance.pdf.

Equator Principles (2011), About the Equator Principles, http://www.equator-principles.com/index.php/aboutep/about-ep.

Equator Principles (2013), The Equator Principles, http://www.equatorprinciples.com/resources/equator_principles_III.pdf.

GCCA (2012), Paving the Way for Climate Compatible Development: Experiences from the Global Climate Change Alliance, http://ec.europa.eu/clima/policies/finance/international/docs/gcca_brochure_2012_repro_lores_en.pdf

GCF (2013), Business Model Framework: Objectives, Results and Performance Indicators, http://www.gcfund.net/fileadmin/00_customer/documents/pdf/B04_03_BMF_Objectives_Results_PerformanceIndicators_10Jun13.pdf.

GEF (2008), Mid-Term Review of the GEF Resource Allocation Framework, Washington, D.C., http://www.thegef.org/gef/sites/thegef.org/files/documents/GEFME-C34-Inf2-RAF_MTR-fulll_rpt.pdf.

GEF (2011a), Evaluation of the Special Climate Change Fund, Washington, D.C., http://www.thegef.org/gef/sites/thegef.org/files/documents/Evaluation\%20for\%20SCCF.pdf.

GEF (2011b), Tracking Tool for Climate Change Mitigation Projects, Washington, D.C., http://www.thegef.org/gef/tracking_tool_CCM.

GEF (2012), Adaptation Monitoring and Assessment Tool (AMAT), Washington, D.C., http://www.thegef.org/gef/tracking_tool_LDCF_SCCF.

GEF (2013), Fiduciary Standards, Washington, http://www.thegef.org/gef/fiduciary_standards.

Gomez, J.J. (2013), Presentation to the first forum of the Standing Committee on Finance, Barcelona, May, 2013.

GoK (Government of Kenya) (2012a), Section A: A Monitoring Reporting Verification System, “Climate Change Action Plan,” Ministry of Environment and Mineral Resources, http://www.kccap.info/index.php?option=com_phocadownload\&view=category\&download=311:section-amonitoring-reporting-verification-system\&id=40:national-performance-and-benefit-measurenment.

GoK (Government of Kenya) (2012b), Section B:Selecting and Monitoring Adaptation Indicators, "Climate Change Action Plan,” Ministry of Environment and Mineral Resources, http://www.kccap.info/index.php?option=com_phocadownload\&view=category\&download=312:section-bselecting-and-monitoring-adaptation-indicators\&id=40:national-performance-and-benefit-measurenment.

GoP (Government of the Philippines) (n.d.), Philippines Climate Change Adaptation Policy Initiatives - National Climate Change Action Plan, Manila, Philippines.

http://www.lga.gov.ph/sites/default/files/knowledgeExchange-pdf/tagaytay/D1-CCC\%20CCADRR\%20Policies\%20and\%20Initiatives.pdf 
GoSA (Government of South Africa) (2013), “Chapter 5: Ensuring environmental sustainability and an equitable transition to a low-carbon economy”, National Development Plan -2030, National Planning Commission, http://www.info.gov.za/view/DownloadFileAction?id=154431.

GPOBA (2012), Output-Based Aid in the Results-Based Financing Universe, http://www.gpoba.org/sites/gpoba.org/files/Output-Based Aid in the Results-Based Financing Universe_0.pdf.

GPOBA (2013), OBA Data, http://www.oba-data.org/.

Green Climate Fund (2011), Governing Instrument for the Green Climate Fund. http://gcfund.net/fileadmin/00_customer/documents/pdf/GCF-governing_instrument-120521-block-LY.pdf.

Hook, S. (2013), What are the practical options for Climate Change Financing, PIFS, http://www.adaptasiapacific.org/sites/default/files/documents/ADAPT\%20Annual\%20Meeting\%202013_Day\% 201_Practical\%20Options\%20for\%20Climate\%20Financing_PIFS_HOOK.pdf

IATI (2013), “The first climate fund signs to IATI,” http://www.aidtransparency.net/news/the-first-climate-financefund-signs-to-iati.

ICCTF (2012), “About: Priority Area”, http://www.icctf.or.id/about/priority-area/.

ICF International (2013), Independent evaluation of the Climate Investment Funds, Interim Report submitted to Evaluation Oversight Committee for the Independent Evaluation of the Climate Investment Funds http://www.cifevaluation.org/cif_inception_report.pdf

IDB (2012), Development Effectiveness Overview, Washington, D.C., http://idbdocs.iadb.org/wsdocs/getdocument.aspx?docnum=37543955.

IEA (2012), "Emissions of $\mathrm{CO}_{2}, \mathrm{CH}_{4}, \mathrm{~N}_{2} \mathrm{O}, \mathrm{HFC}$, PFC and $\mathrm{SF}_{6}$ ", IEA CO $\mathrm{CO}_{2}$ Emissions from Fuel Combustion Statistics (database), http://www.oecd-ilibrary.org/energy/data/iea-co2-emissions-from-fuel-combustionstatistics_co2-data-en.

IEA (2013), Tracking Clean Energy Progress, Paris, http://www.iea.org/publications/TCEP_web.pdf.

IEG (2011), Assessing IFC's Poverty Focus and Results, World Bank Group, Washington, D.C., http://ieg.worldbankgroup.org/content/dam/ieg/IFC/ifc_poverty_full_eval.pdf.

IEG (2012), Designing a Results Framework for Achieving Results: a How-to Guide, World Bank Group, Washington, D.C.,

http://siteresources.worldbank.org/EXTEVACAPDEV/Resources/designing_results_framework.pdf

IFC (2012a), SEF Dia Vikas,

http://www.ifc.org/ifcext/spiwebsite1.nsf/a24f910d8d23aa078525753d00658ca8/d84ed2e2bdbed60885257a860 073131e?opendocument.

IFC (2013), IFC GHG Portfolio Accounting, http://www.ifc.org/wps/wcm/connect/Topics_Ext_Content/IFC_External_Corporate_Site/CB_Home/Policies+a nd+Tools/GHG_Accounting/.

IIGCC (2011), Global Investor Statement on Climate Change, http://www.iigcc.org/_data/assets/pdf_file/0017/15281/2011-Investor-Global-Statement-FINAL-NOTEMBARGOED.pdf.

IPCC (2007), Fourth Assessment Report: Working Group III: Mitigation of Climate Change, http://www.ipcc.ch/publications_and_data/ar4/wg3/en/ch12-ens12-2-4-6.html.

JICA (2011), Support Program to Respond to Climate Change (SPRCC) in Vietnam, http://www2.ir3s.utokyo.ac.jp/icssasia2011/pdf/presentation_paralel/Odajima.pdf.

KFW (2011), Measuring Outcomes, Assessing Results, Learning for the Future, https://www.kfwentwicklungsbank.de/Download-Center/Dokumente-Evaluierung/11_Englisch.pdf. 
Khan, S.M, S. Huq, and M. Shamsuddoha (2012), “The Bangladesh National Climate Funds”, LDC Paper Series, IIED and ECBI, http://dcclimate.files.wordpress.com/2012/05/bangladeshnationalfund.pdf.

Lamhauge, N., E. Lanzi and S. Agrawala (2012), "Monitoring and Evaluation for Adaptation: Lessons from Development Co-operation Agencies", OECD Environment Working Papers, No. 38, OECD Publishing.doi: $10.1787 / 5 \mathrm{~kg} 20 \mathrm{mj} 6 \mathrm{c} 2 \mathrm{bw}-\mathrm{en}$

Lattanzio, R. (2013), International Climate Change Financing: The Climate Investment Funds (CIFs), Congressional Research Service, Washington, D.C, http://www.fas.org/sgp/crs/misc/R41302.pdf.

Ma, C.S. (2013), Climate Finance: The Cambodia Experience, http://unfccc.int/files/cooperation_support/financial_mechanism/longterm_finance/application/pdf/climate_finance_-_the_cambodian_experience.pdf.

Maclellan, N. (2011), Improving Access to Climate Finance for the Pacific Islands, Lowy Institute for International Policy, http://www.lowyinstitute.org/files/pubfiles/Maclellan\%2C_Improving_access_to_climate_financing_web.pdf.

Mani, M. (2012), Assessing the Investment Climate for Climate Investments, Policy Research Paper 6211, http://wwwwds.worldbank.org/servlet/WDSContentServer/WDSP/IB/2012/09/27/000158349_20120927081935/Rendered/ PDF/wps6211.pdf.

Manjate, M.T.A. (2013), Building a Monitoring and Evaluation Framework for Climate Change in Mozambique, presentation at OECD DAC Task Team Meeting, April, 2013.

Martins, Guilherme Guimarães (2013), Tracking the Effectiveness of Climate Finance: the Cases of the Amazon and the Brazilian Climate Funds, Brazilian National Development Bank. Presentation at the CCXG Global Forum, September 2013, Paris, http://www.oecd.org/env/cc/2a\%2004-

2013\%20BNDES_Tracking\%20the\%20Effectiveness\%20of\%20Climate\%20Finance\%20vfinal\%20copy.pdf.

MFSG (Methane Finance Study Group) (2013), Using Pay-for-Performance Mechanisms to Finance Methane Abatement, World Bank Group,

http://siteresources.worldbank.org/EXTCARBONFINANCE/Resources/Methane_Finance_Study_Group_Repo rt.pdf.

Morden, C. (2013), Environmental Fiscal Reform, Carbon Tax \& Climate Finance in South Africa, National Treasury of South Africa, presentation at the UNFCC Experts Meeting on Long-term Finance, July 2013, Makati City, Philippines, http://unfccc.int/files/cooperation_support/financial_mechanism/long-

term_finance/application/pdf/environmental_fiscal_reform_carbon_tax_and_climate_finance_in_south_africa.p df.

Mulenga, Charles (2013), "Monitoring and Evaluation Framework for Tracking the Results of Adaptation Projects in the Context of Zambia", Zambia Institute of Environmental Management, presentation at the CCXG Global Forum, September 2013, Paris, http://www.oecd.org/env/cc/5a\%2002\%20Climate\%20Finance\%20Effectiveness\%20MULENGA.pdf.

Nelson, F. (2013), Samoa: National progress report on the implementation of the Hyogo Framework for Action (2011-2013) - interim, http://www.preventionweb.net/files/28739_wsm_NationalHFAprogress_2011-13.pdf.

Norrington-Davies, G. (2011), Climate Change Financing and Aid Effectiveness: Cameroon Case Study, OECD and AfDB, http://www.oecd.org/dac/environment-development/48458409.pdf.

OECD (1991), Principles for Evaluation of Development Assistance, Paris, http://www.oecd.org/dac/evaluation/50584880.pdf.

OECD (2002), Glossary of Key Terms in Evaluation and Results Based Management, Paris, http://www.oecd.org/dac/evaluation/2754804.pdf.

OECD (2007), Aid Effectiveness: Overview of the Results, 2006 Survey on Monitoring the Paris Declaration, Paris, http://www.oecd.org/dac/effectiveness/39112140.pdf 
OECD (2009), Integrating Climate Change Adaptation into Development Co-operation: Policy Guidance, Paris, http://www.oecd.org/dac/43652123.pdf.

OECD (2011a), Climate Finance and Aid Effectiveness: Lessons Learnt from Development Assistance, Paris, http://oecdinsights.org/2011/08/16/climate-finance-lessons-from-aid-effectiveness/.

OECD (2011b), Busan Partnership for Effective Development Co-operation, $4^{\text {th }}$ High Level Forum on Aid Effectiveness, Busan, Republic of Korea, http://www.oecd.org/dac/effectiveness/49650173.pdf.

OECD (2012), What are the benefits of using country systems? Policy Brief 3, Task Force on Public Financial Management, Paris, http://www.oecd.org/development/effectiveness/48780926.pdf.

OECD (2013a), DAC Criteria for Evaluation Development Assistance, Paris, http://www.oecd.org/dac/evaluation/daccriteriaforevaluatingdevelopmentassistance.htm.

OECD (2013b), M\&E of Climate Change Adaptation: Lessons from OECD Member and Non-Member Countries, http://www.oecd.org/development/effectiveness/48780926.pdf

OECD (2013c), Climate Adaptation Marker: Quality Review, Paris, Presentation at the OECD Environment Workshop on Rio markers, climate and development finance, 24-25 June 2013.

OECD (2012), Aid Effectiveness 2011: Progress in Implementing the Paris Declaration, http://www.oecdilibrary.org/development/aid-effectiveness-2011_9789264125780-en.

OPIC (2009), Greenhouse Gas/Clean Energy Initiative Fact Sheet, Washington, D.C., http://www.opic.gov/sites/default/files/docs/ghg_fact-sheet_070109.pdf.

Pritchett, L. and Sandefur, J. (2013), “Context Matters for Size : Why External Validity Claims and Development Practice Don’t Mix”, Working Paper, No. 336, Center for Global Development, Washington, http://www.cgdev.org/content/publications/context-matter-for-size.

SDC (n.d.), “Climate Change”, http://www.deza.admin.ch/en/Home/Themes/Climate_change.

SE4ALL (2012), A Digest of Comments Submitted During the Consultation on the SE4ALL Global Tracking Framework, http://www.sustainableenergyforall.org/images/content/GTF\%20Consultations\%20on\%20Methodology.pdf.

SE4ALL (2013), Sustainable Energy for All: Global Tracking Framework Overview, http://www.sustainableenergyforall.org/images/Global_Tracking/5-gtf_overview.pdf.

SIDBI (2012), Financing Schemes for Energy Efficiency and Cleaner Production, http://sidbi.in/?q=financingschemes-energy-efficiency-cleaner-production.

Sierra, K., T. Roberts, M. de Nevers, C. Langley, and C. Smith (2013), First Steps Towards a Quality of Climate Finance Scorecard (QUODA-CF), Brookings Institute and the Center for Global Development, http://www.brookings.edu/ /media/research/files/reports/2013/07/climate-finance-scorecard-sierra-roberts/07climate-finance-scorecard-sierra-roberts.pdf

Smallridge, D. and B. Buchner (2012), The Role of National Development Banks in Catalyzing International Climate Finance, http://idbdocs.iadb.org/wsdocs/getdocument.aspx?docnum=37644150.

Stadelmann, M., Castro, P. and Michaelowa, A. (2011), Is There a Leverage Paradox in Climate Finance? Efficiency of the CDM and the GEF in Leveraging Funds and Reducing $\mathrm{CO}_{2}$, Climate Strategies, London, http://www.climatestrategies.org/research/our-reports/category/71/324.html.

Thamrin, Syamsidar (2013), “Indonesia Climate Change Trust Fund: Climate Change Financing Tracking Mechanism”, Indonesia Climate Change Trust Fund. Presentation at CCXG Global Forum. September 2013, Paris.

Thornton, Nigel (n.d.), Realising the Potential: Making the Most of Climate Change Finance in Africa - A synthesis report from six country studies: Cameroon, Ghana, Kenya, Morocco, South Africa and Tanzania, http://www.oecd.org/dac/environment-development/48597031.pdf 
TNC (The Nature Conservancy) (2012). Climate Finance Readiness: Lessons Learned in Developing Countries, Arlington, VA. http://change.nature.org/wp-content/uploads/TNC-Climate-Finance-Readiness.pdf.

UK DFID (2013), Draft - Key Performance Indicators for the UK International Climate Fund, personal communication.

UN AGF (2010), Work Stream 7: Public Interventions to Stimulate Private Investment in Adaptation and Mitigation, http://www.un.org/wcm/webdav/site/climatechange/shared/Documents/AGF_reports/Work_Stream_7 _Public_Private.pdf.

UNDP (2012), Readiness for Climate Finance, New York, NY. http://www.undp.org/content/dam/undp/library/Environment and Energy/Climate Strategies/Readiness for Climate Finance_12April2012.pdf.

UNEP (2013), Global Trends in Renewable Energy Investment 2013, UNEP Frankfurt School and BNEF, http://fsunep-centre.org/publications/global-trends-renewable-energy-investment-2013.

UNFCCC (1992), United Nations Framework Convention on Climate Change, New York, http://unfccc.int/resource/docs/convkp/conveng.pdf.

UNFCCC (1998), Decision 3/CP.4, http://unfccc.int/resource/docs/cop4/16a01.pdf

UNFCCC (2010), Decision 1/CP.16, http://unfccc.int/resource/docs/2010/cop16/eng/07a01.pdf.

UNFCCC (2011), Decision 2/CP.17, http://unfccc.int/resource/docs/2011/cop17/eng/09a01.pdf.

UNFCCC (2012a), Decision 1/CP.18, http://unfccc.int/resource/docs/2012/cop18/eng/08a01.pdf.

UNFCCC (2012b), National Greenhouse Gas Inventory Data for the Period 1990-2010, FCCC/SBI/2012/31, http://unfccc.int/resource/docs/2012/sbi/eng/31.pdf.

USG (United States Government) (2012), Master Indicator List, U.S. Department of State, Washington, D.C., http://www.state.gov/documents/organization/207793.pdf.

World Bank (2012), International Financial Institution Framework for a Harmonised Approach to Greenhouse Gas Accounting, Washington, D.C., http://www.worldbank.org/content/dam/Worldbank/document/IFI_Framework_for_Harmonized_Approach\%20 to_Greenhouse_Gas_Accounting.pdf.

World Bank (2013a), Results-Based Financing in the Energy Sector: An Analytical Guide, Technical Report 004/13, ESMAP, http://www.esmap.org/sites/esmap.org/files/FINAL_ResultsBased\%20Financing\%20in\%20the\%20Energy\%20Sector_TR004-13_Short1.pdf.

World Bank (2013b), World Development Indicators, http://data.worldbank.org/data-catalog/world-developmentindicators.

World Bank (n.d.), About BCCRF, http://siteresources.worldbank.org/INTBANGLADESH/Resources/AboutBCCRF.pdf.

Zou, S. and S. Ockenden (2013). What Enables Effective International Climate Finance in the context of Development Co-operation?, OECD, Paris, forthcoming. 


\section{Glossary}

\begin{tabular}{|c|c|}
\hline AAA & Accra Agenda for Action \\
\hline $\mathrm{ADB}$ & Asian Development Bank \\
\hline $\mathrm{AF}$ & Adaptation Fund \\
\hline AFD & Agence Française de Développement (French development bank) \\
\hline AfDB & African Development Bank \\
\hline $\mathrm{AI}$ & Annex I countries (to the UNFCCC) \\
\hline AMC & Advanced Market Commitment \\
\hline AusAID & Australian Agency for International Development \\
\hline BCCRF & Bangladeshi Climate Change Resilience Fund \\
\hline BNEF & Bloomberg New Energy Finance \\
\hline CB & Capacity building \\
\hline CCT & Conditional Cash Transfer \\
\hline CCXG & Climate Change Expert Group (of the OECD + IEA) \\
\hline CDM & Clean Development Mechanism \\
\hline CHUEE & China Utility based Energy Efficiency financing programme (of the IFC) \\
\hline CIDA & Canadian International Development Agency \\
\hline CIF & Climate Investment Funds \\
\hline COD & Cash on Delivery aid \\
\hline COP & Conference of the Parties (of the UNFCCC) \\
\hline CP3 & Climate Public Private Partnership (of the U.K.) \\
\hline CPEIR & Climate Change Public Expenditure and Institutional Review \\
\hline CPI & Climate Policy Initiative \\
\hline CRS & Creditor Reporting Systems (of the OECD DAC) \\
\hline CTF & Clean Technology Fund (of the CIF) \\
\hline DAC & Development Assistance Committee (of the OECD) \\
\hline DECC & Department for Energy and Climate Change (of the U.K.) \\
\hline DFI & Development finance institution \\
\hline DFID & Department for International Development (of the U.K.) \\
\hline DNA & Designated National Authority \\
\hline DRR & Disaster Risk Reduction \\
\hline EBRD & European Bank for Reconstruction and Development \\
\hline EC & European Commission \\
\hline EIB & European Investment Bank \\
\hline ESCII & Energy Sector Carbon Intensity Index \\
\hline FIP & Forest Investment Program (of the CIF) \\
\hline GBS & General Budget Support \\
\hline GCF & Green Climate Fund \\
\hline GDP & Gross Domestic Product \\
\hline
\end{tabular}




\begin{tabular}{|c|c|}
\hline GEEREF & Global Energy Efficiency and Renewable Energy Fund \\
\hline GEF & Global Environment Facility \\
\hline GHG & Greenhouse gas \\
\hline GIZ & Gesellschaft für Internationale Zusammenarbeit (German development agency) \\
\hline GPOBA & Global Partnership on Output-Based Aid \\
\hline GW(h) & Gigawatt (hours) \\
\hline IBRD & International Bank for Reconstruction and Development \\
\hline ICCTF & Indonesian Climate Change Trust Fund \\
\hline ICF & International Climate Fund (of the U.K.) \\
\hline IDB & Inter-American Development Bank \\
\hline IEA & International Energy Agency \\
\hline IEG & Independent Evaluation Group (of the World Bank Group) \\
\hline IFC & International Finance Corporation \\
\hline IFI & International financial institution \\
\hline IIGCC & International Investors Group on Climate Change \\
\hline IPCC & Intergovernmental Panel on Climate Change \\
\hline JICA & Japan International Cooperation Agency \\
\hline KfW & Kreditanstalt für Wiederaufbau (German development bank) \\
\hline LDC & Least Developed Countries \\
\hline LDCF & Least Developed Country Fund \\
\hline MDB & Multilateral development bank \\
\hline MFI & Multilateral financial institution \\
\hline MRV & Measurement, reporting, and verification \\
\hline MW(h) & Megawatt (hours) \\
\hline NAI & Non-Annex I countries (to the UNFCCC) \\
\hline NAMA & Nationally Appropriate Mitigation Action \\
\hline NAPA & National Adaptation Programme of Action \\
\hline NDB & National development bank \\
\hline NIE & National implementing entity \\
\hline $\mathrm{NOx}$ & Nitrogen oxides \\
\hline OBA & Output-Based Aid \\
\hline ODA & Official Development Assistance \\
\hline ODI & Oversees Development Institute \\
\hline OECD & Organisation for Economic Co-operation and Development \\
\hline OOF & Other Official Flows \\
\hline OPIC & Overseas Private Investment Company \\
\hline PFM & Public Financial Management \\
\hline PPCR & Pilot Program for Climate Resilience (of the CIF) \\
\hline $\mathrm{RBF}$ & Results-based finance \\
\hline RDB & Regional Development Bank \\
\hline REDD+ & Reducing Emissions from Deforestation and Forest Degradation \\
\hline SCF & Strategic Climate Fund (of the CIF) \\
\hline
\end{tabular}




$\begin{array}{ll}\text { SCF } & \text { Standing Committee on Finance } \\ \text { SE4ALL } & \text { Sustainable Energy For All initiative } \\ \text { SEI } & \text { Sustainable Energy Initiative (of the EBRD) } \\ \text { SIDA } & \text { Swedish International Development Agency } \\ \text { SIDS } & \text { Small Island Developing States } \\ \text { SOx } & \text { Sulphur oxides } \\ \text { SPRCC } & \text { Support Programme to Respond to Climate Change (of Vietnam) } \\ \text { STAR } & \text { System for the Transparent Allocation of Resources (of the GEF) } \\ \text { TA } & \text { Technical assistance } \\ \text { UNDP } & \text { United Nations Development Programme } \\ \text { UNEP } & \text { United Nations Environment Programme } \\ \text { UNFCCC } & \text { United Nations Framework Convention on Climate Change } \\ \text { USAID } & \text { US Agency for International Development } \\ \text { USD } & \text { United States Dollars } \\ \text { WBG } & \text { World Bank Group }\end{array}$




\section{www.oecd.org/env/cc/ccxg.htm}

\section{www.iea.org}

